DOE Project on Heavy Vehicle Aerodynamic Drag

\title{
UCRL-TR-227076
}

Rose McCallen, Kambiz Salari, Jason Ortega, Paul Castellucci, David Pointer, Fred Browand, James Ross, Bruce Storms

January 5, 2007 
This document was prepared as an account of work sponsored by an agency of the United States government. Neither the United States government nor Lawrence Livermore National Security, LLC, nor any of their employees makes any warranty, expressed or implied, or assumes any legal liability or responsibility for the accuracy, completeness, or usefulness of any information, apparatus, product, or process disclosed, or represents that its use would not infringe privately owned rights. Reference herein to any specific commercial product, process, or service by trade name, trademark, manufacturer, or otherwise does not necessarily constitute or imply its endorsement, recommendation, or favoring by the United States government or Lawrence Livermore National Security, LLC. The views and opinions of authors expressed herein do not necessarily state or reflect those of the United States government or Lawrence Livermore National Security, LLC, and shall not be used for advertising or product endorsement purposes.

This work performed under the auspices of the U.S. Department of Energy by Lawrence Livermore National Laboratory under Contract DE-AC52-07NA27344. 


\section{DOE Project on Heavy Vehicle Aerodynamic Drag}

Project Principal Investigator: $R$. C. Mc Callen

Lawrence Livermore National Laboratory

P.O. Box 808, Livermore, CA 94551-0808

(925) 423-0958; mccallen1@llnl.gov

Principal Investigator: K. Salari

Co-Investigators: J. Ortega, P. Castellucci

Lawrence Livermore National Laboratory

P.O. Box 808, Livermore, CA 94551-0808

(925) 424-4635; salari1@,llnl.gov

Principal Investigator: W. D. Pointer

Co-Investigators: J. Chang, S. Singh, E. Dringenberg

Argonne National Laboratory

9700 S. Cass Avenue, NE-208, Argonne, IL 60439

(630) 252-1052; dpointer@anl.gov

Principal Investigator: F. Browand

Co-Investigators: C. Radovich, T. Merzel, D. Plocher

Aerospace \& Mechanical Engineering, University of Southern California

RRB 203, Los Angeles CA 90089-1191

(213) 740-5359; e-mail: browand@spock.usc.edu

Principal Investigator: J. Ross

Co-Investigators: B. Storms

NASA Ames Research Center

MS 260-1, Moffett Field, CA 94035

(650)604-6722; jcross@mail.arc.nasa.gov

Technology Development Manager: Lee Slezak

202-586-2335,Lee.Slezak@EE.DOE.GOV

Technical Program Manager: Jules Routbort

630-252-5065, routbort@anl.gov

Contractor: Lawrence Livermore National Laboratory, Argonne National Laboratory, NASA Ames Research Center 
Contract No.: W-7405-ENG-48, W-31-109-ENG-38, DE-AI01-99EE50559

\section{Objective}

Class 8 tractor-trailers consume $11-12 \%$ of the total US petroleum use. ${ }^{1}$ At high way speeds, $65 \%$ of the energy expenditure for a Class 8 truck is in overcoming aerodynamic drag. The project objective is to improve fuel economy of Class 8 tractor-trailers by providing guidance on methods of reducing drag by at least $25 \%$. A $25 \%$ reduction in drag would present a $12 \%$ improvement in fuel economy at highway speeds, equivalent to about 130 midsize tanker ships per year. Specific goals include:

- Provide guidance to industry in the reduction of aerodynamic drag of heavy truck vehicles.

- Develop innovative drag reducing concepts that are operationally and economically sound.

- Establish a database of experimental, computational, and conceptual design information, and demonstrate the potential of new drag-reduction devices.

\section{Approach}

- Develop and demonstrate the ability to simulate and analyze aerodynamic flow around heavy truck vehicles using existing and advanced computational fluid dynamics (CFD) tools.

- Through an extensive experimental effort, generate an experimental data base for code validation and for understanding of key drag producing flow characteristics

- Provide industry with design guidance and insight into flow phenomena from experiments and computations.

- Investigate aero devices (e.g., base flaps, tractor-trailer gap stabilizer, underbody skirts and wedges, blowing and acoustic devices), provide industry with conceptual designs of drag reducing devices, and demonstrate the full-scale fuel economy potential of these devices.

\section{Accomplishments}

- Organized and lead a very successful annual DOE Heavy Vehicle Working Group Meeting with active industry participation. The objective of these annual meetings is to provide a forum for reviewing industry needs, presenting new drag reduction concepts, discussing project direction, and identifying areas of collaboration between industry and DOE supported R\&D participants from National Labs, universities and other research organizations. Participants comprised major industrial representatives: Freightliner, PACCAR, Kenworth, International, Cummins, Michelin,

\footnotetext{
${ }^{1}$ U.S. DOE, Transportation Energy Data Book, 24th Edition, http://cta.ornl.gov/data/new_for_edition24.sht, U.S. DOT, FHA, Highway Statistics, 2002
} 
Eaton, along with small company representation: Laydon, Aerovolution, Aero Industries, Mach Zero Associates.Highlights of the meeting were

o Interest in new flow conditioning concept of a "bleeding flow" device for trailer base and tractor base.

o Identified need for experimental and computational methods for evaluation of design options, e.g., optimization methods and tools

o Importance of vehicle integration for achieving goal to double vehicle efficiency, e.g., geometry/shaping, power source/drive-train, tire/road
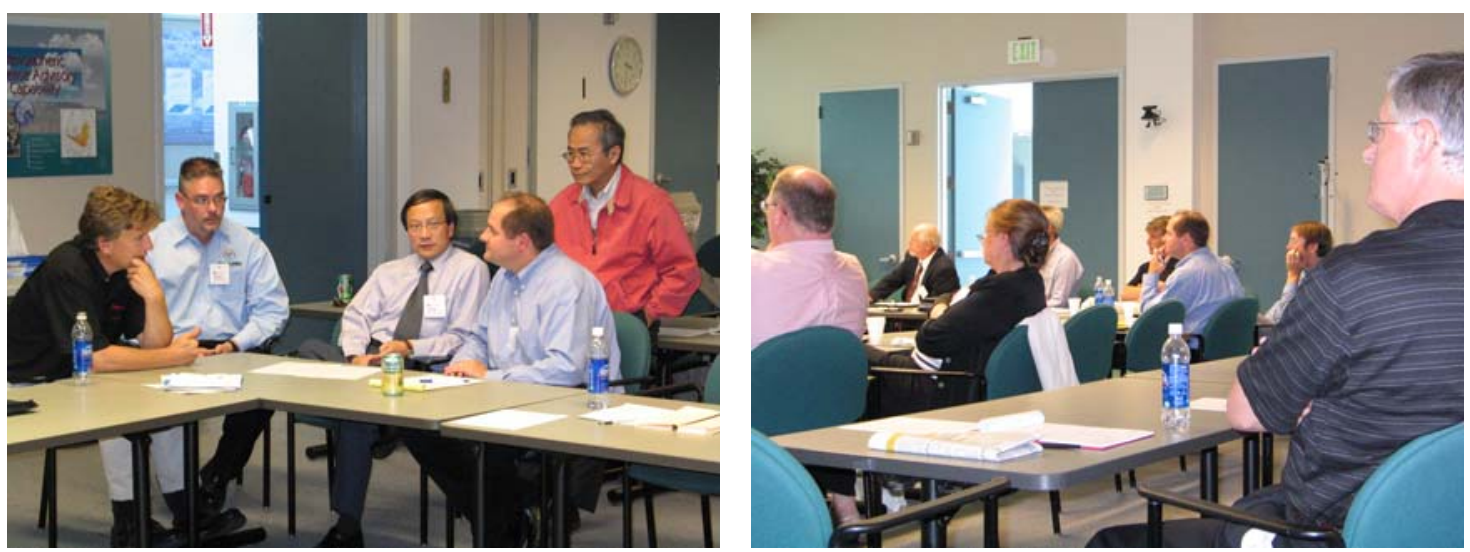

Left Photo: Representatives from (left to right) Freightliner, PACCAR, Kenworth, International, and Cummins take advantage of opportunity during meeting to form a breakout group to discuss common interests

Right Photo: Participants from (left to right) Michelin USA, Mach Zero Associates, Michelin International Office, Freightliner, International, NASA, and Eaton during formal presentations by government, industry, and DOE Aero Team

- New flow conditioning concept of "bleeding-flow" device has been shown computationally to provide significant gap flow and trailer base drag reduction. Plans are to perform reduced-scale tests at NASA and full-scale tests at NRC

- Providing a consistent, realistic, comprehensive assessment of the energy balance when evaluating devices like with the "bleeding flow" device is needed. Consider and report:

0 energy used by active features

o weight of all components

o Impact of design on fleet operation in terms of dollars saved per ton hauled in addition to changes in drag coefficient or fuel use rate.

o Yaw-averaged drag values when evaluating design changes.

- Tractor and trailer underbody experiments at NASA show small improvement in tractor drag with the use of tractor belly pans or with the covering of cross ribs under the trailer. Experiments also showed that trailer side skirts are still the most promising drag reduction approach.

- Evaluation of the impact of small changes in radiator or grille dimensions has revealed that the total drag is not particularly sensitive to those changes. 
- A preliminary computation of the effect of wet roads on rolling resistance indicates a significant impact on fuel economy.

- Spray experiments at USC in collaboration with Michelin have demonstrated the effect of tire treatments as a possible spray mitigation options.

\section{Future Direction}

- Getting devices on road

o From understanding of key flow mechanisms, develop less obtrusive and optimized device concepts

o Demonstration wind tunnel, track, and road tests by leveraging work with National Research Council of Canada, TMA/DOE, and seek collaborative demonstrations with fleet owners and operators

- Economic/duty cycle evaluation with PSAT (ANL's system model)

o Provide mechanistic data: strong variation in drag per yaw, speed, geometry/devices, environment, etc

- Develop and transfer technology and information to industry

o Perform full-scale wind tunnel experiments of bleeding flow device in collaboration with tractor manufacturer

o Contouring the tractor hood reduces the grille area, also reducing coolant flow. In addition, underhood exhaust gas recirculation to meet EPA 2007 regulation requires more underhood cooling. With industry encouragement, we are including underhood flow in aerodynamic drag computations to provide insight into the coupled flow phenomena.

o Identified need for experimental and computational methods for evaluation of design options for improved efficiency, e.g., optimization methods and tools.

o Experiments at USC in collaboration with Michelin will provide some guidance on methods to minimize wet road effect on rolling resistance.

- Leverage Program work and seek funding from other agencies.

\section{$\underline{\text { Introduction }}$}

The following reports on the findings and accomplishments for fiscal year 2005 in the project's three focus areas

- Drag reduction devices

- Experimental testing

- Computational modeling
Detailed reports from each participating organization are provided in the appendices. Included are experimental results by NASA and USC, and complimentary computations by LLNL, ANL in Appendices A through D.

Drag Reduction Devices and Future Plans 
There are three areas identified for aero drag reduction and several drag reduction devices have been investigated

- Tractor-Trailer Gap

Stabilizing devices, cab extenders

- Wheels/Underbody

Skirts/wedge and lowboy trailer

- Trailer Base

Boattail plates, base flaps, rounded edges, and pneumatics

Over $12 \%$ increase in fuel economy is possible, e.g.,

$>4 \%$ trailer base-flaps

$>6 \%$ trailer skirts

$>\underline{2 \%}$ gap splitter plate

$>12 \%$ Total

Unfortunately, these devices have operational and maintenance issues. With our understanding of the key flow mechanisms, we are developing less obtrusive and optimized innovative design concepts using computational fluid dynamics and experiments. In addition, to getting devices on the road, consequences with aerodynamic improvements need to be addressed.
Addressing these consequences of aerodynamic improvements is an important task in getting devices on the road. Our efforts in the development of device concepts and device optimization will accomplish this. These issues are also of interest to other government agencies (e.g., DOT and EPA) and industry (i.e., Michelin is providing partial support for experiments at USC). The rolling resistance and splash and spray effort will continue to receive complimentary support from industry and we will actively seek joint government funding.

\section{Acknowledgments}

This work was performed under the auspices of the U.S. Department of Energy by University of California, Lawrence Livermore National

Laboratory under Contract W-7405-Eng48. This work has been completed under the auspices of the U.S. Department of Energy by the University of Chicago as Operator of Argonne National Laboratory ("Argonne") under Contract No. W-31-109-ENG-38. 


\title{
APPENDIX A
}

\section{Heavy Vehicle Flow Conditioning: Application to the Tractor/Trailer Gap and Trailer Base}

\author{
Kambiz Salari, Jason Ortega, Paul Castelucci \\ Lawrence Livermore National Laboratory \\ 7000 East Ave, L-098, Livermore, CA 94551 \\ 925-423-0958, Fax 925-422-3389, mccallen1@llnl.gov \\ Technology Development Manager: Lee Slezak \\ 202-586-2335, Lee.Slezak@EE.DOE.GOV \\ Technical Program Manager: Jules Routbort \\ 630-252-5065,routbort@anl.gov
}

Contractor: Lawrence Livermore National Laboratory

Contract No.: W-7405-ENG-48

\section{Objective}

The goal of this study is to reduce the aerodynamic drag of a heavy vehicle by bleeding low speed air into the tractor/trailer gap and into the trailer wake.

\section{Approach}

To alleviate the aerodynamic drag that arises from the flow separating off the trailer base and from cross-flow in the tractor/trailer gap, a low speed bleeding flow is introduced into the trailer wake and into the tractor/trailer gap, respectively. The idea to pursue this method of drag reduction came out of discussions with the fleets regarding their needs and operational concerns about the present drag reduction devices and methodologies. Numerical simulations are performed on two representative heavy vehicle geometries. The aerodynamic drag coefficients are computed for various bleeding speeds and bleeding areas. Wind tunnel experiments will be conducted to validate the computational results. In preparation for these experiments, a reduced-scale heavy vehicle wind tunnel model is fabricated with a rapid-prototyping technique.

\section{Accomplishments}

\section{Bleeding flow into the tractor/trailer gap and into the trailer wake is shown to reduce the aerodynamic drag}

The computational fluid dynamics (CFD) simulations demonstrate that bleeding air from the trailer base reduces the aerodynamic drag coefficient of a heavy vehicle by as much as $0.03-0.05$. When the bleeding flow is applied to the tractor/trailer gap, the reduction in the drag coefficient ranges from $0.06-0.35$, depending on the heavy vehicle geometry and the vehicle yaw angle. 


\section{Wind Tunnel Experiments to Validate the Bleeding Flow Results}

To confirm the effectiveness of bleeding flow into the trailer wake or into the tractor/trailer gap, wind tunnel experiments will be performed on a reduced-scale heavy vehicle model at NASA Ames in FY07. Given our collaboration with Freightliner and our upcoming full-scale tests in the Freightliner wind tunnel in FY07, we selected a Freightliner Columbia tractor for testing in the NASA Ames wind tunnel. The Columbia model is fabricated using a selective laser sintering (SLS) rapid-prototyping technique, which will allow a performance comparison of tractor/trailer gap bleeding, traditional side extenders, a complete gap sealer, traditional base flaps, and trailer base bleeding. Through these wind tunnel experiments, we will gain a deeper understanding into the physics behind tractor/trailer and tractor base bleeding.

\section{Near Term Directions}

- Pursue a deeper understanding into the drag reduction performance of base bleeding

- Approach industry, fleets, and third party manufacturers for performing road tests with the base bleeding concept

- Conduct wind tunnel measurements on a reduced-scale heavy vehicle model at NASA Ames

- Perform CFD simulations to model the base bleeding flow physics

- Collaborate with Freightliner and the National Research Council (NRC) of Canada to make full-scale aerodynamic drag measurements of a heavy vehicle with a bleeding flow

\section{Far Term Directions}

- Collaborate with industry and the fleets to devise additional drag reduction concepts that can integrate heavy vehicles and lead to a reduction in fuel usage

- Understand underbody flow and thermal management

\section{Motivation and Background}

In November 2005, LLNL members of the Heavy Vehicle Aerodynamic Drag project spoke with Mr. Marty Fletcher of US Xpress at the 2005 SAE Commercial Vehicle Engineering conference regarding industry's perspective of heavy vehicle drag reduction devices. During the conversation that ensued, Mr. Fletcher expressed his concerns about the current and proposed devices for drag reduction. In particular, $\mathrm{Mr}$. Fletcher explained the maintenance issues he had been experiencing with tractor side extenders and similar concerns he had regarding the proposed trailer base flaps. One of his suggestions was to investigate the feasibility of using air injection to condition the flow in the tractor/trailer gap and in the trailer wake, thus mitigating these sources of aerodynamic drag. The potential advantage this technique is that it would eliminate the large, easily damaged structural surfaces present in the side extenders and base flaps designs. Based upon this recommendation, we initiated a study to determine if air injection could be utilized as a means for reducing heavy vehicle aerodynamic drag.

A review of the literature demonstrated that there have been two main approaches in using air injection to reduce the aerodynamic drag of a bluff 
body, such as a heavy vehicle. The first is to fabricate peripheral slots around the base of the bluff body and to inject air through these slots (Freund \& Mungal, 1994). Straight or curved plates are positioned adjacent to these slots so that the high-speed jets turn the separating shear layers into the wake and, thereby, increase the trailer base pressure. Employing this method on a full-scale heavy vehicle, Engler (2004) showed that it is possible to reduce the fuel usage by as much as $4 \%$ (not considering the fuel consumption to run a required blower or compressor). The second approach is to bleed air over a large portion of the bluff body base. Wood (1964, 1967) and Bearman (1967) showed that sufficient base bleed can increase base pressure and reduce the base drag. Furthermore, Yao \& Sandham (2002) found that bleeding air over a large area at a low velocity is much more effective in reducing the drag than bleeding over a small area at a high velocity. Since large area bleeding had not been applied to heavy vehicles, the LLNL members decided upon applying the latter approach to the tractor and trailer bases as a means of reducing heavy vehicle drag.

\section{Computational Simulations}

To evaluate the effectiveness of base bleeding, computational fluid dynamics simulations are performed on two fullscale heavy vehicle geometries (Figure 1). The first geometry (Figure 1a), labeled MGTS, is a representation of a cab-over-engine tractor, while the second (Figure 1b), labeled GCM, is a representation of a conventional tractor. Due to the simplified nature of the MGTS and GCM, their gap geometries differ slightly from that of a full-scale heavy vehicle. For example, the MGTS has a thin plate that covers a portion of the gap bottom, while the GCM has a completely closed gap bottom.

Trailer base bleeding is tested on the GCM by specifying an area over the trailer base (Figure 2) that injects air into the downstream direction. Several bleeding flowrates are defined for each bleeding area. Additionally, the GCM is positioned at 0 degrees relative to the freestream velocity, $U_{\text {inf }}$, for the trailer base bleeding simulations. Tractor base bleeding is tested on both the MGTS and the GCM by injecting air over the entire tractor base (Figure 3). For the GCM, the vehicle is yawed at 7 degrees relative to the freestream velocity to simulate the vehicle traveling within a crosswind. For the MGTS, yaw angles of 0 and 7 degrees are investigated. Additionally, a performance comparison is made on the MGTS with traditional tractor side extenders, which have been shown in previous experiments and simulations to be effective in reducing the drag when the vehicle operates within a crosswind. A commercial CFD code (STARCD, www.cd-adapco.com) is used to solve for the velocity, pressure, and turbulent quantities about the two heavy vehicle geometries.

The simulations demonstrate that both trailer and tractor base bleeding are effective in reducing the heavy vehicle drag coefficient, $\mathrm{C}_{\mathrm{d}}$. Figure 4 shows the drag coefficient as function of the bleeding area and bleeding flow rate for trailer base bleeding on the GCM. It is evident that a greater reduction in drag is achieved at the higher bleeding flowrates. Figure 5 shows that the two largest bleeding areas alter the structure 
of the separated wake by displacing it in the downstream direction. A similar phenomenon has been observed by Wood (1967), Bearman (1967), Yao \& D. Sandham (2002), and Sevilla \& Martinez-Bazan (2004).

Figures 6 and 7 show the drag coefficients for the tractor base bleeding configurations. On the MGTS, it is evident that tractor base bleeding is more effective at reducing the drag at both yaw angles than the traditional side extenders. Since bleeding flow is computationally introduced on the trailer or tractor base by means of a simple boundary condition, it is not possible to get a proper estimate of the actual power requirements needed to produce the bleeding flow. However, our future fullscale wind tunnel experiments at NASA Ames and Freightliner will help provide us with this information.

Figure 8 highlights the physical mechanism by which tractor base bleeding functions. It can be seen that without tractor base bleeding there is a significant cross flow from the freestream into the gap between the tractor and trailer. As the cross flow exits on the leeward side of the vehicle, it does not remain attached to the trailer, but separates massively. When tractor base bleeding is introduced, very little freestream flow enters the gap and the massive separation bubble is dramatically reduced. Analysis of the pressure over the tractor base and trailer front demonstrates that tractor base bleeding reduces the drag primarily by increasing the pressure over the tractor base (Figure 9).

Since simulating the separated wake of the trailer and tractor/trailer gap poses a challenge for Reynolds averaged NavierStokes (RANS) turbulence models, LLNL is currently developing a hybrid turbulence model that utilizes a RANS model near the vehicle surface and a large eddy simulation (LES) model farther away from the surface. When complete, this advanced turbulence model will allow for a more accurate performance evaluation of devices, such as trailer base flaps and side extenders, that are typically located near massively separated flow regions.

\section{Wind Tunnel Experiments to Validate the Bleeding Flow Results}

While the CFD results show promise for the tractor and trailer base bleeding concepts, it is necessary to confirm these findings with experimental measurements. To achieve this, we will conduct a wind tunnel study at NASA Ames during FY07. Measurements will be made on a scale representation of a Freightliner tractor that employs both tractor and trailer base bleeding. To ensure that the tractor properly characterizes the full-scale vehicle, we corresponded with Mr. Matt Markstaller at Freightliner. The CAD model was then fabricated with a SLS method that captures the fine-scale details of an actual Columbia tractor (Figure 10). The trailer component of the model will be designed and fabricated at NASA Ames, who is providing its 3' $x$ 4' lowspeed wind tunnel for aerodynamic testing in FY07.

\section{References}

Bearman, P.W. 1967 The effect of base bleed on the flow behind a twodimensional model with a blunt trailing edge, Aero. Quart., 18, 207-224. 
Englar, R.J. 2004 Pneumatic heavy vehicle aerodynamic drag reduction, safety enhancement, and performance improvement, The Aerodynamics of Heavy Vehicles: Trucks, Buses, and Trains, Lecture Notes in Applied and Computational Mechanics, 19, 277-302.

Freund, J.B. \& Mungal, M.G. 1994 Drag and wake modification of axisymmetric bluff bodies using Coanda blowing, J. Aircraft, 31(3), 572-78.

Sevilla, A. \& Martinez-Bazan, C. 2004 Vortex shedding in high Reynolds number axisymmetric bluff-body wakes: local linear instability and global bleed control, Phys. Fluids, 16(9), 3460-3469.

Wood, C.J. 1964 The effect of base bleed on a periodic wake, J. Roy. Aero. Soc., 68, 477-482.

Wood, C.J. 1967 Visualization of an incompressible wake with base bleed, $J F M$, 29(2), 259-272.

Yao, Y.F. \& Sandham, N.D. 2002

Direct numerical simulation of turbulent trailing-edge flow with base flow control, AIAA J., 40(9), 1708-1716.

a)

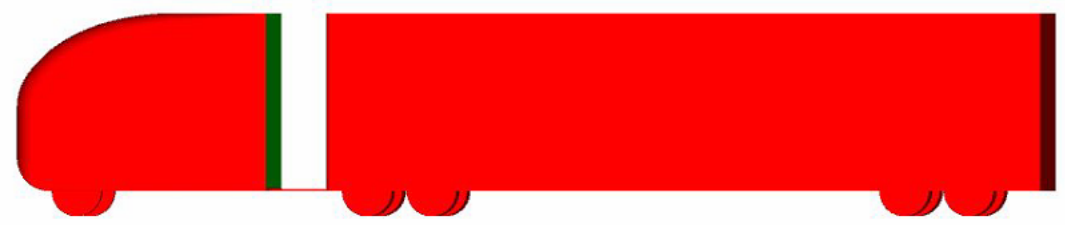

b)
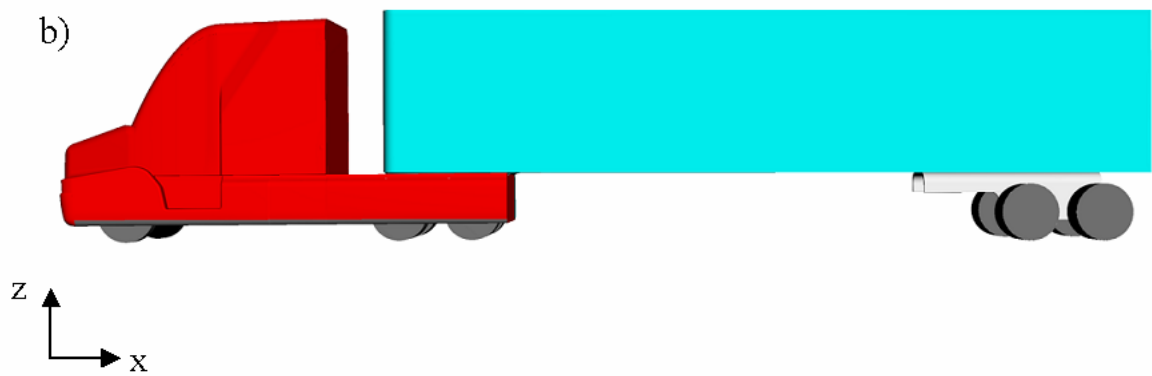

Figure 1. a) MGTS and b) GCM heavy vehicle geometries used for testing the tractor and trailer base bleeding concept. 


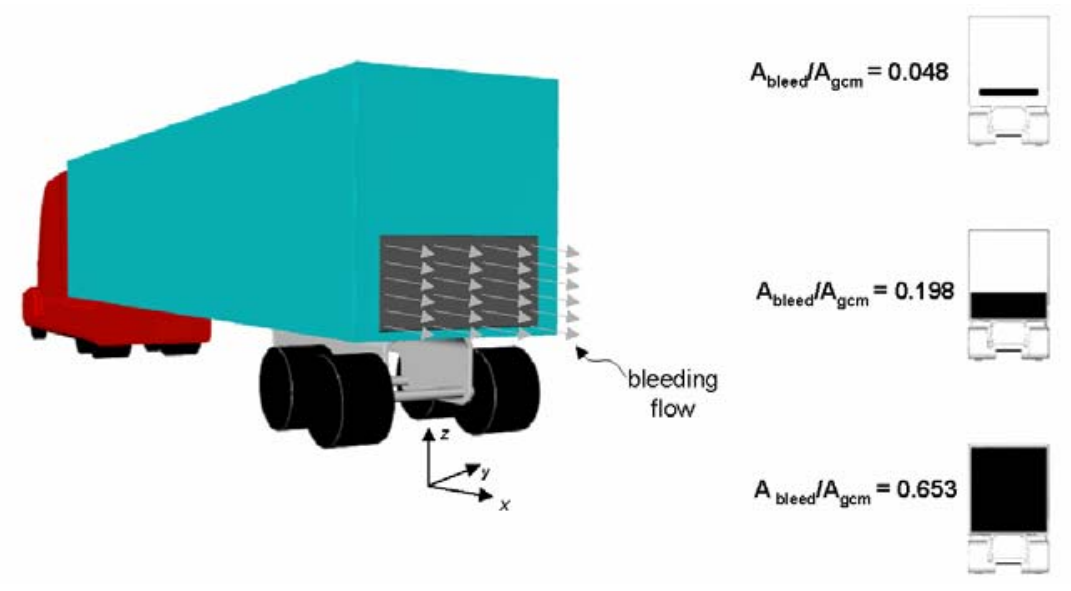

Figure 2. Trailer base bleeding areas on the GCM. $A_{\text {bleed }}$ denotes the bleeding area and $\mathrm{A}_{\mathrm{GCM}}$ the cross-sectional area of the GCM vehicle.

a)

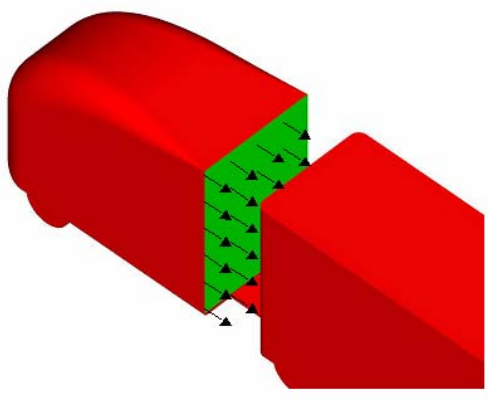

b)

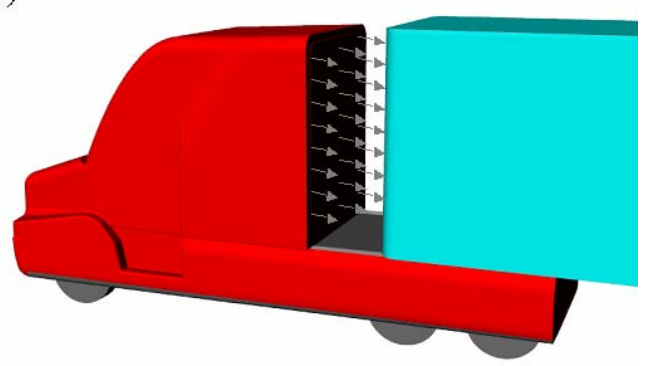

Figure 3. Location of tractor base bleeding for the a) MGTS and b) GCM. 


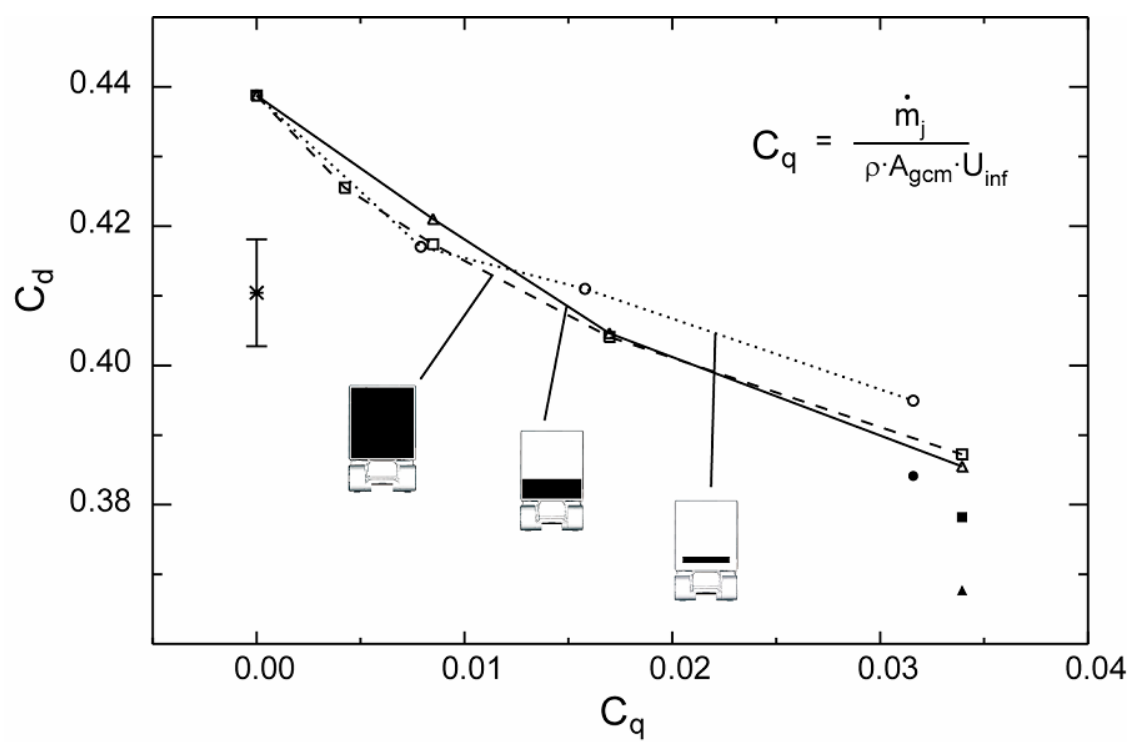

Figure 4. Drag coefficient as a function of bleeding area and bleeding coefficient, $\mathrm{C}_{\mathrm{q}}$, for trailer base bleeding on the GCM, where $m_{j}$ is the bleeding mass flowrate and $\rho$ the density of air. 
a)

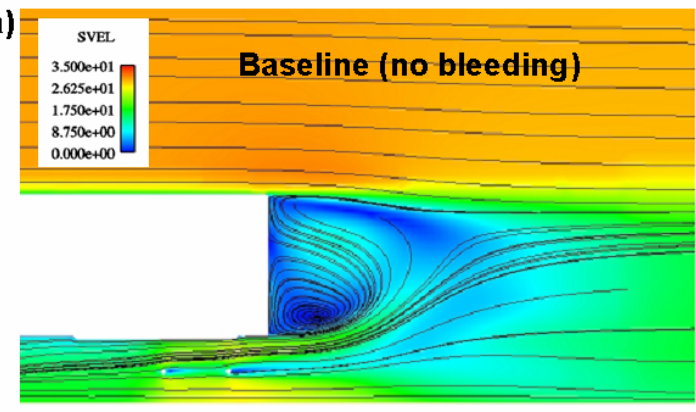

c)

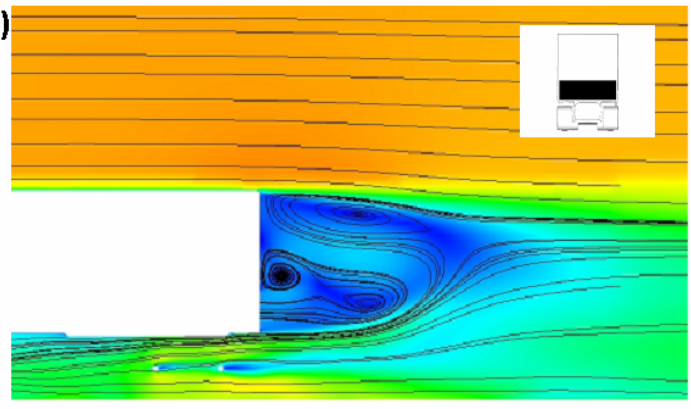

b)

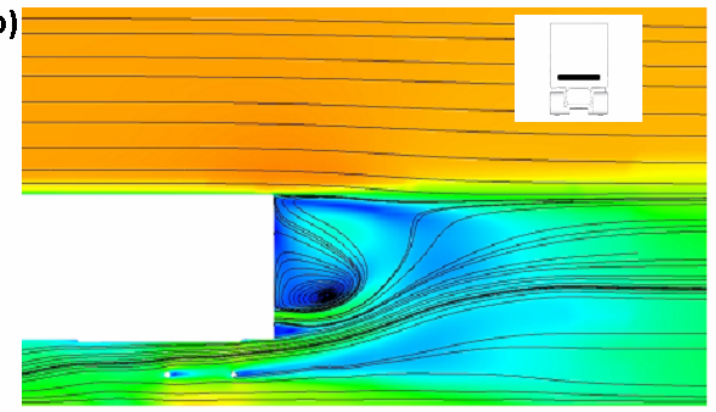

d)

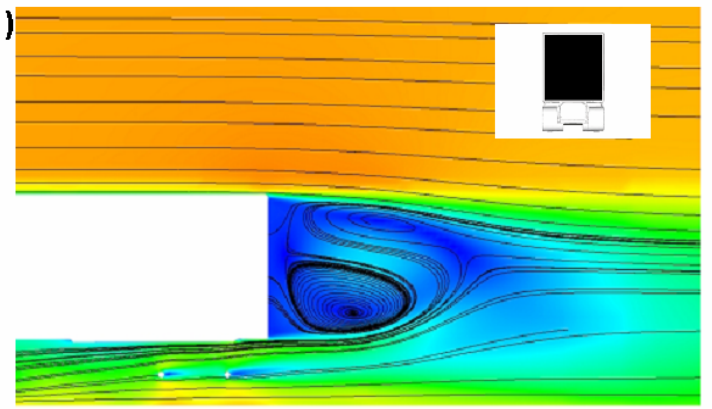

Figure 5. Mid-plane velocity magnitude (color contours) and velocity streamlines in the wake of GCM a) without and b-d) with trailer base bleeding $\left(\mathrm{C}_{\mathrm{q}} \approx 0.03\right)$.

\begin{tabular}{|c|c|c|c|c|}
\hline Yaw angle & \multicolumn{2}{|c|}{$0^{\circ}$ yaw } & \multicolumn{2}{c|}{$7^{\circ}$ yaw } \\
\hline & $\mathrm{C}_{\mathrm{D}}$ & $\Delta \mathrm{C}_{\mathrm{D}}$ & $\mathrm{C}_{\mathrm{D}}$ & $\Delta \mathrm{C}_{\mathrm{D}}$ \\
\hline Baseline & 0.401 & & 0.496 & \\
\hline Cab extenders & 0.393 & -0.008 & 0.457 & -0.039 \\
\hline Flow conditioning & 0.344 & -0.057 & 0.400 & -0.096 \\
\hline
\end{tabular}

Figure 6. Drag coefficients for tractor base bleeding $\left(\mathrm{C}_{\mathrm{q}}=0.05\right)$ on the MGTS at 0 and 7 degrees yaw. 


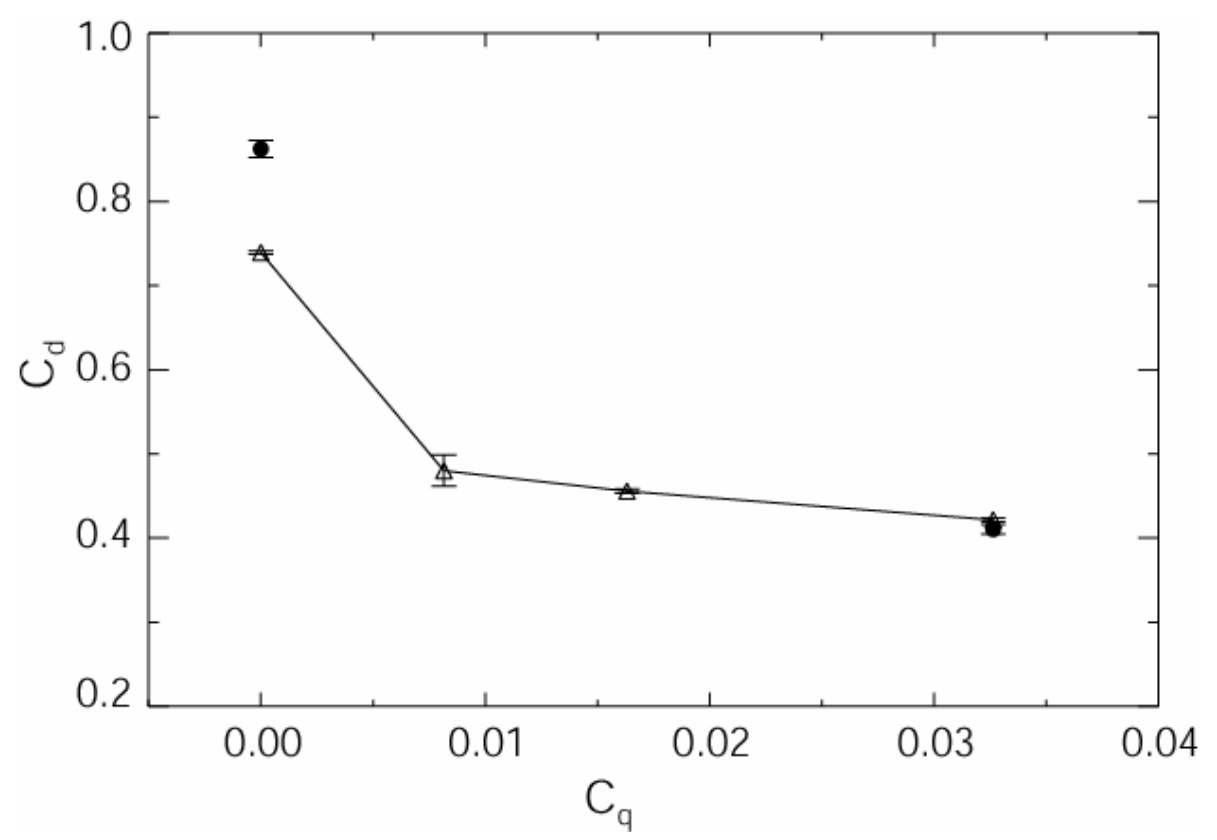

Figure 7. Drag coefficients as a function of the bleeding coefficient, $\mathrm{C}_{\mathrm{q}}$, for tractor base bleeding on the GCM at 7 degrees yaw.
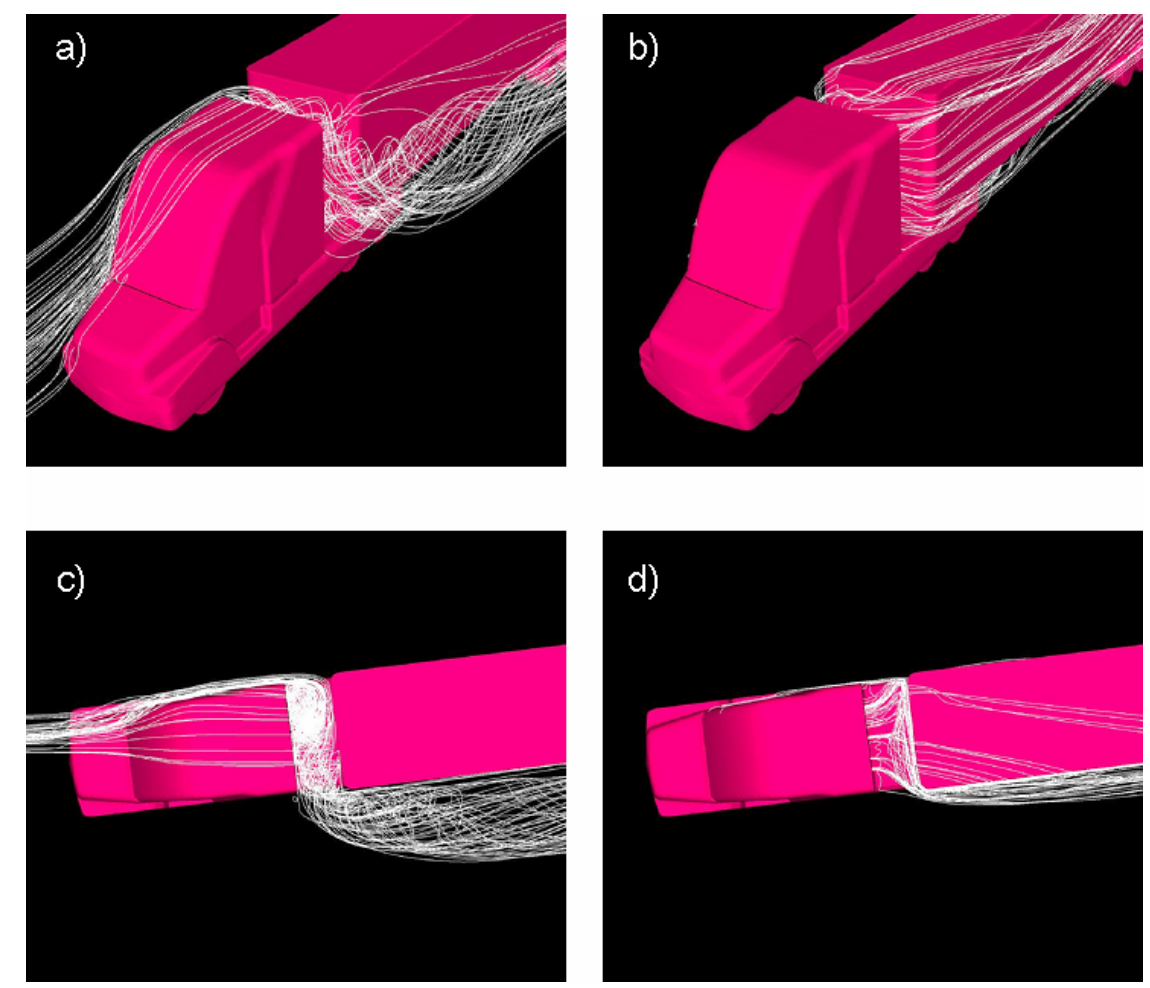
Figure 8. Velocity streamlines in the gap of the GCM a,c) without and b,d) with tractor base bleeding.
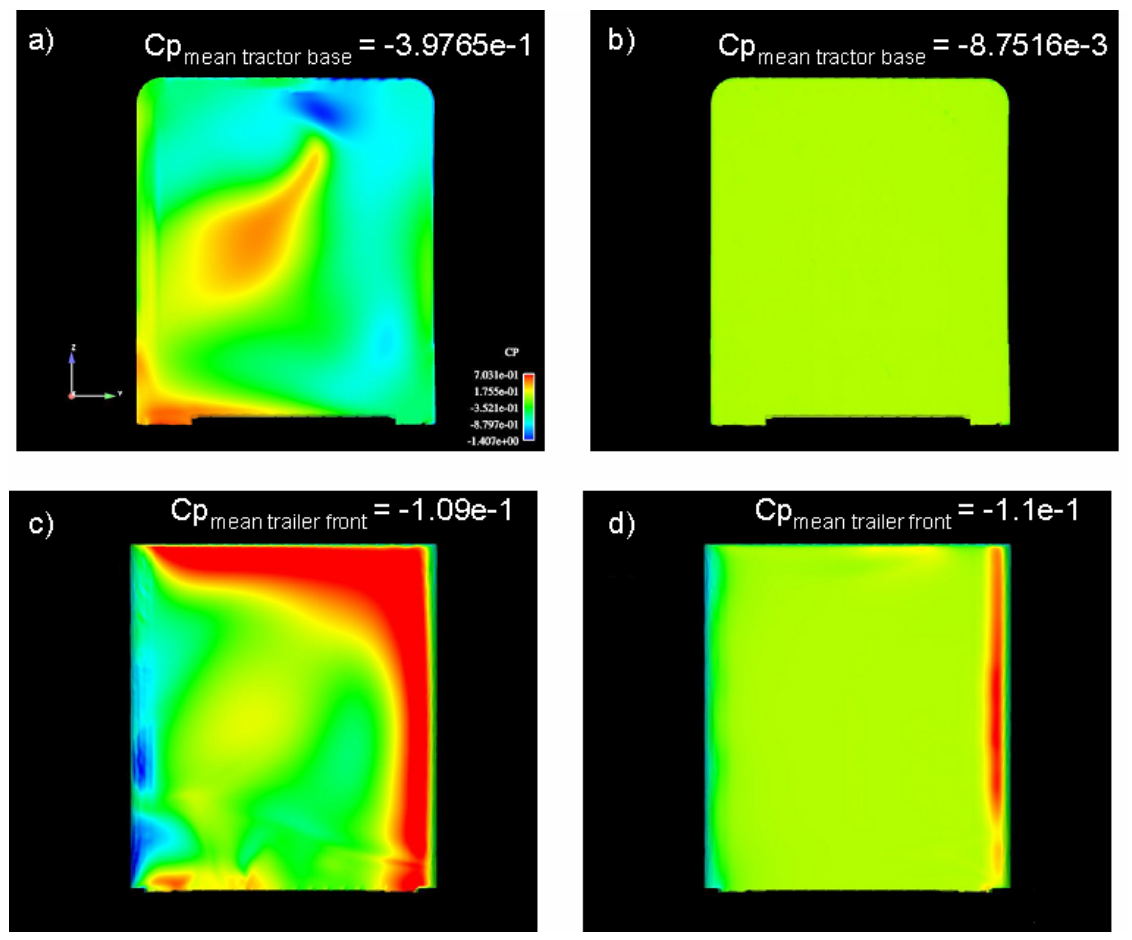

Figure 9. Pressure distribution over the $a, b)$ tractor base and $c, d$ ) trailer front $a, c)$ without and $b, d)$ with tractor base bleeding on the GCM. $C_{p}=p /\left(1 / 2 \rho U_{\text {inf }}^{2}\right)$ is defined to be the pressure coefficient, where $\mathrm{p}$ is the pressure.

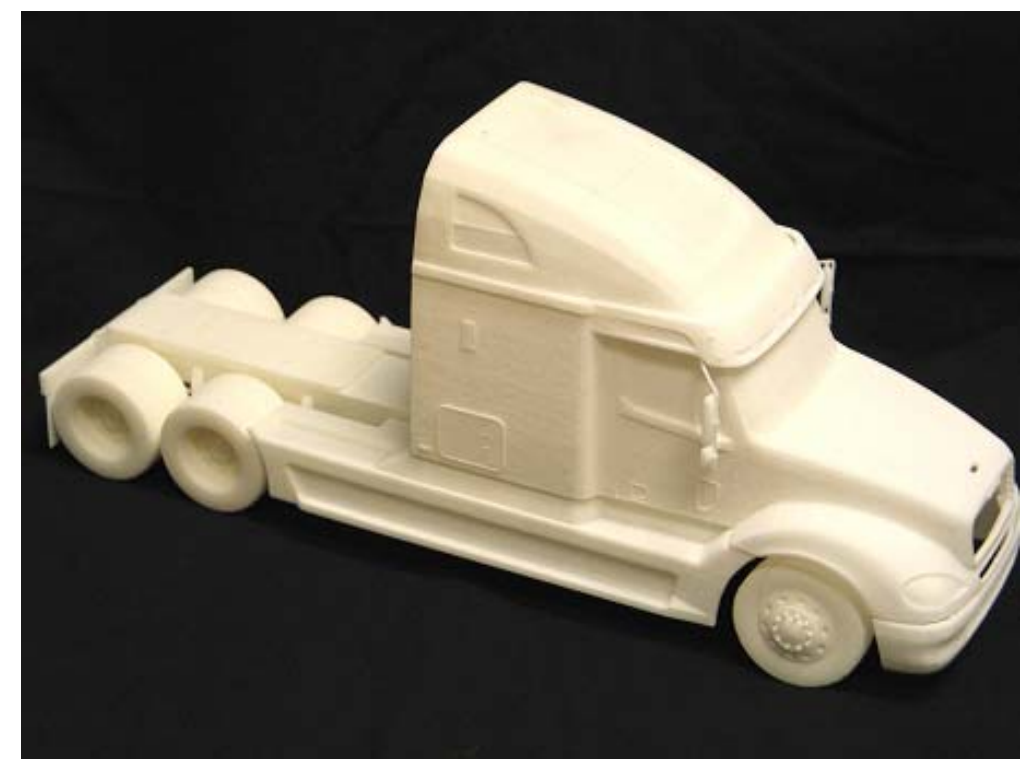


Figure 10. Wind tunnel model (1:20 scale) for testing the tractor and trailer base bleeding concepts at NASA Ames in FY07. 


\title{
APPENDIX B
}

\section{Experimental Measurement of the Flow-field of Heavy Trucks}

\author{
Principal Investigator: Fred Browand \\ Aerospace \& Mechanical Engineering, University of Southern California \\ RRB 203, Los Angeles CA 90089-1191 \\ (213) 740-5359; fax: (213)740-7774; e-mail: browand@spock.usc.edu
}

Technology Development Manager: Lee Slezak

202-586-2335,Lee.Slezak@EE.DOE.GOV

Technical Program Manager: Jules Routbort

630-252-5065, routbort@anl.gov

Contractor: Lawrence Livermore National laboratory

Subcontract No.: B545349

\section{Objective}

Improve the performance of heavy trucks by reducing aerodynamic drag, rolling resistance, and by increasing safety.

\section{Approach}

Water spray from heavy truck tires is an important safety issue. The spray decreases the rearward visibility of the truck drivers. For automobiles in the immediate vicinity, spray obscures the roadway on either side of the truck. We study the fundamental mechanisms of spray formation.

Water on the roadway also increases the rolling resistance of tires by the momentum expended to move the water out of the way. No direct measurements of rolling resistance are presently available in the literature, but we estimate the change in rolling resistance due to water on the roadway to be significant.

\section{Accomplishments}

\section{Preliminary tests illuminate the mechanisms of spray formation.}

For the first time, the complex process of spray formation from rolling tires has been documented in the laboratory. Visualizations reveal the major mechanism of break-up to be the result of the instability of thin sheets of water that form between the roadway and the tire.

\section{Propose modifications to the apparatus for the study of rolling resistance on a wet roadway.}

In the laboratory apparatus two tires are rolled in contact with one another. One tire simulates the presence of the road surface. Water is injected from a specially designed injector placed just upstream of the contact patch. 
The speed of the injected water jet is the peripheral speed of the tires. Sensors can be added to the apparatus to measure change in the rolling force as water is applied.

\section{Future Direction}

Initiate a program of rolling resistance measurement using the newly constructed apparatus. Continue study of tire spray formation, and methods to mitigate spray.

\section{Changes in Rolling Resistance Due to a Wet Roadway}

We can estimate the magnitude of the additional force felt by a tire due to the water as it rolls over a flooded road. In a coordinate system moving with the vehicle, the water on the roadway represents an oncoming flow which is diverted laterally and brought to rest at a stagnation point at the front of the tire. The order of magnitude of the force exerted by the flow on the two front tires in this process is

$$
F=\rho U^{2}(t \times W),
$$

where $\rho$ is the density of water, $U$ is the velocity, $t$ is the depth of the water and $W$ is the width of the tires. Substituting representative values for these variables, we see a vehicle traveling $27 \mathrm{~m} \mathrm{~s}^{-1}$ (60 $\mathrm{mph})$, with $t=3 \mathrm{~mm}$ (1/8 inch) and $W=8$ cm (3 1/8 inches) must overcome an additional resistance of about $175 \mathrm{~N}$ (40 lbs.) - the same order of magnitude as the rolling resistance. Experiments with an airplane taxiing on a flooded runway show an additional resistance due to the

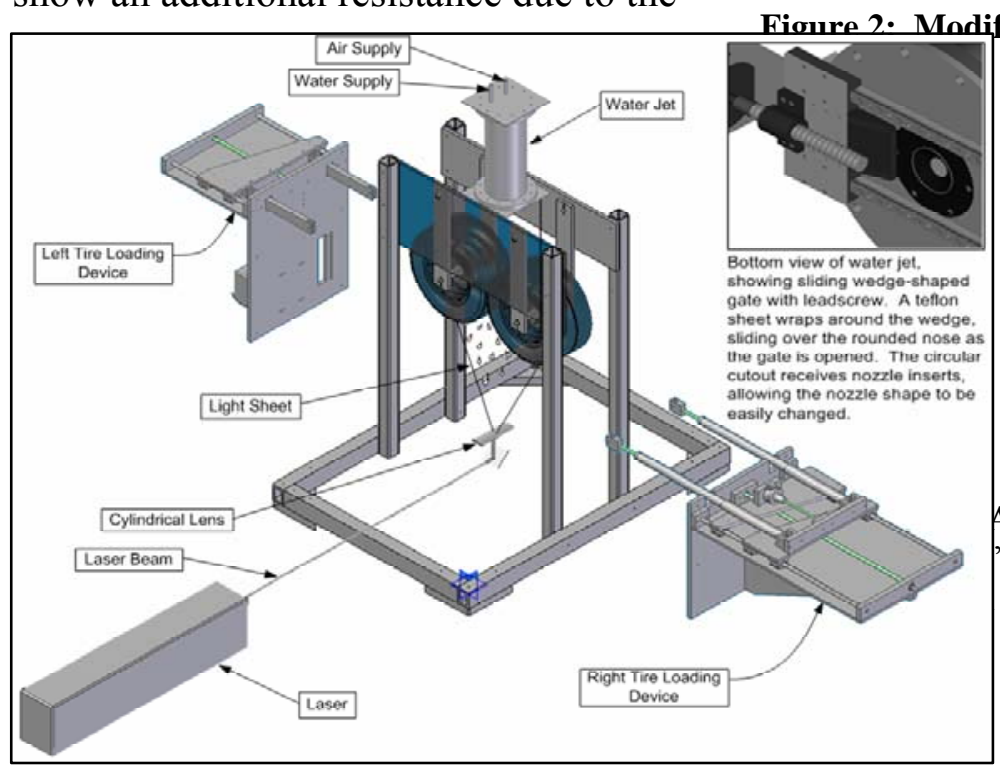

water of about $10-11 \%$ of the airplane's weight. ${ }^{2}$ This additional resistance due to displacing water can be added to the rolling resistance and aerodynamic drag as forces that the vehicle's engine must work against to maintain forward motion.

Continuing in a reference frame moving with the vehicle, we could treat the roadway not as a solid surface, but as an imaginary plane between the rolling tire and its image located below the surface. The layer of water still flows toward the tire at a speed $U$, producing the resistance force described above.
Our plans are to measure this additional force

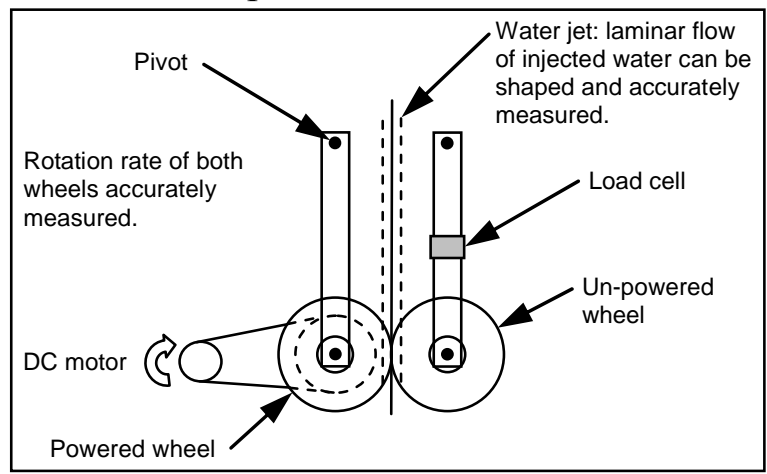

using the tire spray apparatu $\mathrm{s}$ at USC (Fig. 1). That machine consists of two tires, each hung from a pendulum arm so the tire treads touch. The pendulum arms are then loaded with a side force pressing the tires together to form a tire patch. This geometry is the same as that in the image view of the problem except the

Adnan Cepic, "Hydroplaning of H-type aircraft ' SAE Transactions 113 part I (SAE paper 200419), pp. 1599-1606, 2004.

Figure 1: The USC tire spray apparatus. 
plane of symmetry is now vertical. One tire is driven by a motor while the other rotates due to its contact with the other tire.

It is important in this configuration that the water is delivered to the tire patch at the circumferential speed of the tire. To do this, a water jet was designed and built. The jet exits through a sharp-edged opening in the bottom of a cylindrical tank, producing a glassysmooth laminar jet. The speed of the jet is controlled by setting the depth of water and the air pressure in the tank while the volume of the flow is controlled through the size of the nozzle.

To measure the force on the non-driven tire load cells will be inserted into the pendulum arms (Fig. 2). With the tires spinning at constant speed, the jet will be turned on. The difference in force measured before the flow and during the flow will be the additional resistance resulting from the tire pushing the water out of its path.

\section{Spray From Rolling Tires}

A continuing part of the project has been looking at spray from a tire rolling over a wet surface. This has been done using illumination both from a laser and via backlighting - shining a bright light on a glass plate mounted behind the tires then looking at the spray from the front. The laser offers the advantage of a very short exposure, about 5 ns, and the limitation of a low framing rate. Backlighting has limitations imposed by the brightness of the light and the characteristics of the video camera, in our case typical exposures of $6 \mu \mathrm{s}$ and framing rates of about $1600 \mathrm{frames} / \mathrm{s}$.
Fig. 3 is a frame from a movie using backlighting and looking at the $25 \mathrm{~cm}$ long region downstream of the tire patch formed between a smooth tire on the bottom and a single-grooved tire on the top. Most prominent is the sheet of water extending between the tire groove and the smooth tread of the opposite tire. Also prominent are the ridges of disturbed water extending through the sheet between the tires.

Looking at these frames more closely one can identify holes developing in the sheets (Fig. 4) and clearly see the texture of another sheet behind. This growing hole in the sheet of water with another sheet behind becomes even clearer when several frames are viewed in succession.

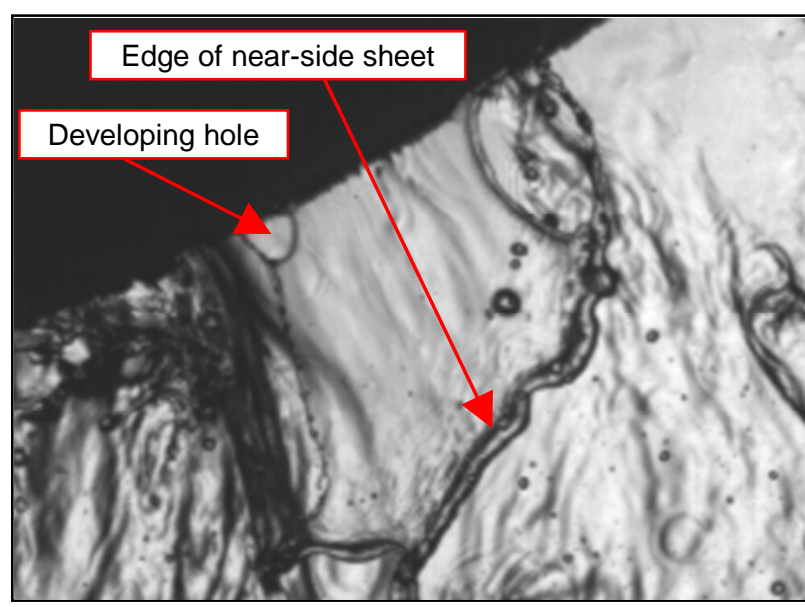

Figure 4: Close up of region from video frame in Fig. 3 showing a developing hole in a sheet with a second sheet behind.

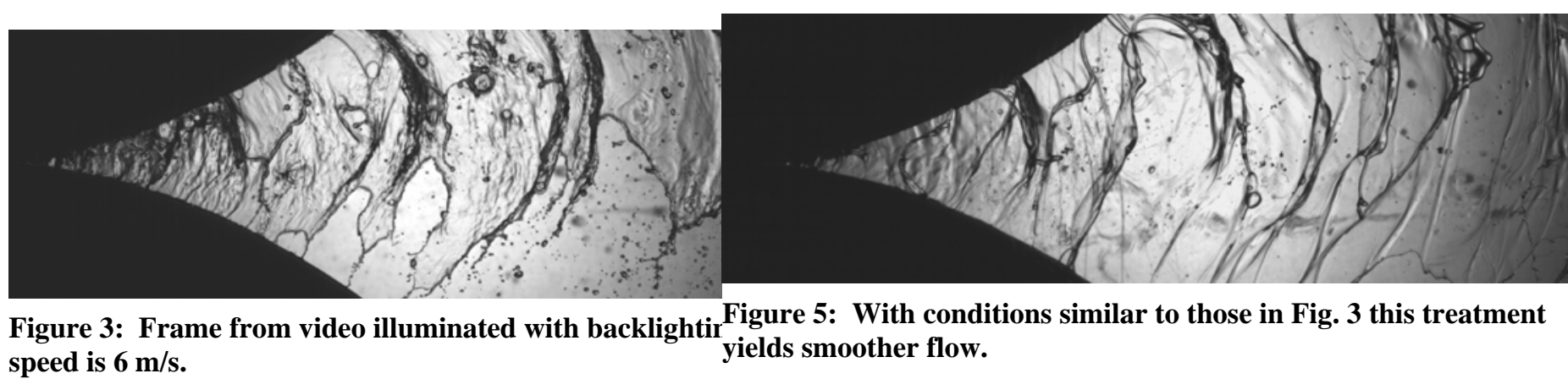


The flow downstream of the tire patch, then, is made up of sheets of water coming from different locations across the tire groove, with thicker bands of water with a rougher surface extending between the two tires. These bands have a preferred spacing. As this pattern moves downstream, the preferred spacing becomes larger and both the sheets and bands separate from the tire surfaces. The sheets form holes which grow until there is only a thin string of water separating adjacent holes.
This thin string then breaks down into small droplets. The preferred spacing of the bands decreases with speed and less sheet formation.

Several different treatments were applied to the spray system. Depending on the treatment, the flow could be made rougher, with less sheet formation at a particular speed or smoothed dramatically as in Fig. 5. 


\title{
APPENDIX C \\ Aerodynamic Drag Reduction of the Underbody of a Class-8 Tractor-Trailer
}

\author{
Principal Investigator: Bruce L. Storms \\ AerospaceComputing, Inc. \\ $M / S / 260-1$ \\ NASA Ames Research Center \\ Moffett Field, CA 94035 \\ (650)604-1356,fax: (650)604-4511,e-mail:bstorms@mail.arc.nasa.gov \\ Field Project Manager: James C. Ross \\ NASA Ames Research Center \\ $M / S / 260-1$ \\ Moffett Field, CA 94035 \\ (650)604-1356, fax: (650)604-4511,e-mail: james.c.ross@nasa.gov \\ Technology Development Manager: Lee Slezak \\ 202-586-2335, Lee.Slezak@EE.DOE.GOV \\ Technical Program Manager: Jules Routbort \\ 630-252-5065,routbort@anl.gov
}

Contractor: NASA Ames Research Center

Contract No.: DE-AI01-99EE50559

\section{A. Aerodynamic Drag Reduction of the Underbody of a Class-8 Tractor- Trailer \\ Objective}

- To investigate the contributions of the tractor and trailer underbody to overall aerodynamic drag.

- To test configurations and devices resulting in aerodynamic drag reduction

\section{Approach}

- Fabricate a 1:20-scale model with a realistic tractor-trailer geometry including significant underbody detail.

- Measure the forces and moments and surface pressure distribution in the 32- by 48-Inch Wind Tunnel. Measurements were made at various yaw angles to study the influence of crosswind and to calculate windaveraged drag coefficients. Several drag-reduction concepts were studied in order to document their potential benefit.

\section{Accomplishments}

- Small-scale study completed of aerodynamic effects of tractor-trailer underbody. 
- Detailed experimental results were presented for several configurations of interest with several tractor and trailer add-on devices to demonstrate the potential of underbody modifications.

o Separate measurements of underbody fairings on the tractor and trailer yielded windaveraged drag reduction of 0.018 for two configurations. A floor plate blocking vertical flow in the tractor-trailer gap resulted in a drag reduction of 0.021 . Trailer side skirts proved to be the most effective trailer-underbody device, reducing the wind-averaged drag by 0.073 .

o The estimated annual fuel savings per truck was calculated assuming a typical use of $240,000 \mathrm{~km} / \mathrm{yr}$. The smooth trailer underbody and side skirts yielded an estimated savings of 1653 and 6586 liters/yr. For the relatively small drag reduction of the smooth underbody configuration, the annual monetary savings for a 5,000 truck fleet (assuming a fuel cost of $\$ 0.83 /$ liter) would be close to $\$ 7$ million.

- The results of the study were presented at the SAE 2006 Commercial Vehicle Engineering Conference in Chicago, IL on November 1st (paper number SAE-2006-01-3532)

\section{Future Direction}

- Additional studies of aerodynamic drag reduction of tractor-trailer gap and trailer base.

\section{Introduction}

For a typical heavy vehicle at a highway speed of $110 \mathrm{~km} / \mathrm{hr}$, the energy required to overcome aerodynamic drag is about $65 \%$ of the total expenditure (which includes rolling friction, transmission losses, and accessories). By altering the vehicle shape, it has been estimated that modern truck drag coefficients may be reduced by up to $50 \%$ resulting in an annual national fuel savings of eleven billion liters (Ref. 1). This large potential savings coupled with increasing fuel costs have spurred renewed interest in heavy-vehicle aerodynamics.

A significant number of experimental studies of heavy-truck geometries were conducted in the 1970's and 1980's (Ref. 2). The resulting firstgeneration drag-reduction technology currently in use includes cab shaping, cab-mounted deflectors, trailer front-end fairings, cab side extenders, and body front-edge rounding. The cab deflectors and side extenders accounted for the majority of the wind-averaged drag reduction reducing the pre-1980 drag level by about $25 \%$. Other drag-reduction technologies that are not widely used include tractor-trailer gap seals, trailer side skirts, and rear boat-tailing. Each of these technologies produce a reduction of the wind-averaged drag coefficient between 0.03 and 0.10 which is about one-half the benefit of the first-generation technologies. However, the benefits of these devices are additive and the resulting net reduction is relatively large.
The aerodynamic drag reduction and fuel savings of various tractor and trailer modifications was previously summarized in Ref. 3. Since fuel consumption is the quantity of interest for commercial operators, a derivation of fuel consumption as a function of drag coefficient and road speed was provided. For trailer base flaps and skirts, the ranges of wind-averaged drag reduction were listed as $0.03-0.09$ and $0.04-0.07$, respectively.

More recently, a series of experimental and computational studies was funded by the Department of Energy (DOE), Office of Heavy Vehicle Technology. With the goal of CFD validation, the experimental efforts have focused on simplified geometries at 1:8-scale and below. Early experiments (Refs. 4-6) focused on the simplified geometry of the Ground Transportation System (GTS) model representative of a class- 8 tractortrailer with a cab-over-engine design. A 1:8-scale GTS model with no tractor-trailer gap and no wheels was first studied with the addition of several ogival boattails and slants to the base of the trailer (Ref. 4). The largest overall drag reduction of $10 \%$ was obtained by a $2.4-\mathrm{m}$ ogive configuration (full scale). The addition of boattail plates to the same model resulted in a $19 \%$ drag reduction and PIV measurements behind the trailer document a significant reduction in the wake size due to the flow turning provided by the plates (Ref. 5). Variation of the tractor-trailer gap on a 1:15-scale model at zero 
yaw revealed relatively constant drag on the tractor while the trailer drag increased by a factor of three as the gap was increased from zero to $1.55^{*} \mathrm{~A} * * 0.5$ (Ref. 6).

Also part of the DOE effort, the Generic Conventional Model (GCM) of the current study was tested in two different facilities at the National Aeronautics and Space Administration's (NASA) Ames Research Center. This geometry included a tractor-trailer gap and a simplified conventional tractor geometry (detailed below). In the $7-$ by $10-\mathrm{Ft}$ Wind Tunnel, measurements were made at a Reynolds number of 1.1 million. Of particular interest are the detailed PIV data in the tractor-trailer gap with and without side extenders and in the trailer wake with and without boattail plates (Ref. 7). A large subset of the configurations tested in the 7by $10-\mathrm{Ft}$ Tunnel were duplicated in the $12-\mathrm{Ft}$ Pressure Tunnel to determine the effects of Reynolds number variation (Ref. 8). For all configurations, Reynolds number effects were evident at high yaw angles (greater than .deg) where there was a significant reduction in drag at lower Reynolds numbers. However, this difference did not significantly affect the computation of the wind-averaged drag coefficients (at highway speeds) which employs data at lower yaw angles.

The goal of the present study is to investigate the potential for drag reduction by geometric modifications of the underbodies of both the tractor and trailer. Large fairings were first attached to the underbodies and gap region to determine the upper limits of possible drag reduction. More practical fairings were subsequently tested for comparison.

\section{Experimental Setup}

The experiments were conducted in the 48- by 32-Inch Subsonic Wind Tunnel in the Fluid Mechanics Laboratory at NASA Ames Research Center (Fig. 1). This facility is an open-circuit, indraft wind tunnel with flow supplied by a singlestage centrifugal compressor acting as a vacuum source. The compressor runs at constant speed while mass flow (and hence, speed) through the test section is controlled by means of a variable-area sonic throat. When running, the compressor fan draws ambient laboratory air through a pleated filter, which prevents the entry of dust and foreign materials into the tunnel. Immediately downstream of the pleated filter are a stainless steel honeycomb and four progressively smaller open-area screens for flow conditioning. The 9:1 contraction leads to the wind tunnel test section, which is approximately 1.2 $\mathrm{m}$ wide, $0.81 \mathrm{~m}$ tall, and $3.05 \mathrm{~m}$ long. The sidewalls and roof of the test section are constructed of thick Plexiglas. Directly above the test section is a constant pressure plenum that houses a 3-axis traverse to which various flow sensors, cameras, lighting, or other equipment can be attached. In addition, the test section floor contains a remotecontrolled rotating yaw platform. The flow exits from the test section through a contraction into the sonic throat. The design maximum velocity in the test section is $52 \mathrm{~m} / \mathrm{s}$, corresponding to a Reynolds Number of approximately 3.5 million per meter. The freestream turbulence levels of the empty test section in the longitudinal, lateral, and vertical directions are approximately $0.15 \%, 0.1 \%$, and $0.1 \%$, respectively. The flow speed and static pressure reference was provided by a pitot-static probe located at $\mathrm{x} / \mathrm{w}=3.1, \mathrm{y} / \mathrm{w}=4.9$, and $\mathrm{z} / \mathrm{w}=$ 3.7.

A three-view drawing of the baseline tractortrailer configuration is shown in Fig. 2. This 1:20scale model is representative of a class- 8 tractortrailer with a standard aero package. The tractor was fabricated by stereolithography from a publicly available geometry of the Kenworth T600A. This unvalidated geometry definition included a full-scale height mismatch between the tractor roof fairing and the top of the trailer of $38 \mathrm{~cm}$ (the actual height of the tractor is unknown due to the proprietary nature of the design). Apart from a standard aero package with cab side extenders and wheel fairings, this geometry includes significant underbody detail as shown in Fig. 3. A 0.4-mm trip wire was located at the front of the model (visible in Fig. 4) to ensure turbulent flow on the tractor. A simplified engine block was also included with the approximate external dimensions of a typical engine. To simulate flow through the engine compartment, a flowthrough front grill with a porosity of $60 \%$ was included to approximate the pressure drop across the radiators.

The trailer geometry was chosen to be representative of modern U.S. designs. The trailer measures $13.7 \mathrm{~m}$ in length (full scale) with rounded front vertical edges ( $20-\mathrm{cm}$ full-scale radius). The underbody includes details of cross-members, landing gear, undercarriage, and other significant 
components (Fig. 3). This geometry was provided by SOLUS with input from Great Dane. The tractortrailer gap for this study was held constant at the full-scale equivalent of $1 \mathrm{~m}(0.39 \mathrm{w})$.

A photograph of the baseline tractor-trailer configuration installed in the 48 - by 32 -Inch Wind Tunnel test section is shown in Fig. 4. The model was attached to the model-support hardware by two $1.9-\mathrm{cm}$ vertical posts. The posts were non-metric (i.e., their aero loads were not measured by the balance) with $3 \mathrm{~mm}$ of clearance as they passed through the trailer floor. Since there was no moving ground plane, the model was mounted with its wheels $5.4 \mathrm{~mm}$ above the ground plane (to account for the tunnel floor boundary layer) and centered laterally in the tunnel. The center of rotation of the model was located $39.5 \mathrm{~cm}$ aft of the tractor front bumper. The model frontal area of $0.025 \mathrm{~m} 2$ gives a solid blockage of $2.5 \%$. The overall model loads were measured with a six-component balance (1.9cm Task balance Mark XV) that was mounted inside the trailer. The manufacturer-specified accuracy of the internal balance in the axial (drag) direction was $\pm 0.33 \mathrm{~N}$, but the experimental results suggest significantly greater accuracy as detailed in the subsequent discussion.

The model was instrumented with 9 pressure taps on the tractor and 66 taps on the trailer. The surface pressures were measured with an electronically scanned pressure system and time averaging yielded an uncertainty in the calculated pressure coefficients of \pm 0.002 at $\operatorname{Re}=430,000$. The model was yawed through a range of angles between \pm 14 degrees.

\section{Results and Discussion}

The results presented below detail the body-axis drag (axial force) for the tractor-trailer combination. This drag coefficient represents the force along the axis of the vehicle in the direction of travel. No wall corrections were applied to the data and all coefficients were calculated based on the dynamic pressure from a pitot-static probe adjacent to the model. Without wall corrections, the computed drag coefficients will differ from those of the equivalent model in free air. However, the measured differences between configurations should be representative of the effects of the associated geometric modifications.
Using the variation of drag with yaw angle, windaveraged drag coefficients $\left(\bar{C}_{D}\right)$ were computed using the SAE Recommended Practice (Ref. 9). This practice assumes that the mean wind speed in the United States of $11.2 \mathrm{~km} / \mathrm{hr}$ has an equal probability of approaching the vehicle from any direction. This mean wind speed and the vehicle velocity were used to calculate a weighted average based on the variation in drag coefficient over a range of yaw angles. The wind-averaged drag coefficients reported in this paper were computed for a highway speed of $90 \mathrm{~km} / \mathrm{hr}$.

Except where noted, the data presented below are from the measurements conducted in the 48- by 32 Inch Wind Tunnel at a Reynolds number of 430,000 and all data were acquired for increasing yaw angle.

\section{A. Baseline Configuration}

Prior to the force and pressure measurements, tufts were applied to the sides of the baseline trailer to provide flow visualization (tufts did not adhere to the tractor due to the nature of the nylon material). Although the test Reynolds number of 430,000 is well below the critical value for this configuration (estimated at 1 million), no large-scale separation was observed on the trailer sides for yaw angles between $\pm 10 \mathrm{deg}$. This suggests that the trip wire and relatively complicated tractor geometry resulted in turbulent downstream flow.

A comparison of the baseline drag curve to that of previously tested configurations is presented in Figure 5. Relative to the 1:8-scale GCM configuration tested at $\mathrm{Re}=1.1$ million (Ref. 8), the drag curve of the 1:20-scale model was significantly higher and exhibited a larger increase with increasing yaw. This result is expected due to the significantly more complicated tractor geometry, the added trailer underbody detail, and the previously noted height mismatch between the tractor and trailer. Relative to a more realistic geometry with a 1:10-scale White Road Boss tractor tested at NRC (Ref. 10), there was relatively good agreement at zero yaw with increasing difference at higher yaw angles. The difference at yaw is possibly a result of the added detail (and corresponding drag) of the current 1:20-scale trailer underbody. There was also some observed asymmetry between positive and negative yaw angles. Data acquired for decreasing yaw (opposite the standard rotation) indicated 
minimal hysteresis, so the drag-curve asymmetry is likely related to small asymmetries in the tractor geometry and/or the facility flow.

During the course of this wind-tunnel study, measurements of the baseline configuration were made four times over a three-day period to demonstrate repeatability. The resulting drag curves (Fig. 6) indicate that the repeatability is on the order of the symbol size, or approximately \pm 0.003 , for yaw angles between $\pm 5 \mathrm{deg}$. For larger angles, the repeatability was about twice this value, or \pm 0.006 . To account for the observed drag-curve asymmetry, the drag coefficients at corresponding positive and negative yaw angles were averaged for the computation of wind-averaged drag. For these four repeat runs, the repeatability of the wind-averaged drag coefficients was \pm 0.002 .

\section{B. Tractor Underbody Fairings}

Two underbody fairings, or belly pans, were studied on the tractor (Fig. 7). Although impractical, a full tractor fairing was tested to determine the maximum drag reduction possible. This fairing was a simple flat plate that extended from the front bumper to the rear axle, enclosing and/or shielding the engine compartment and underbody components. In addition, a partial tractor fairing was tested that was identical to the full fairing, but only extended to the rear of the cab. The resulting drag curves (Fig. 8) indicate that the benefit of the tractor fairings is the greatest for yaw angles between $\pm 5 \mathrm{deg}$, resulting in wind-averaged drag reduction of 0.015 and 0.018 for the partial and full fairings, respectively.

\section{Tractor-Trailer Gap Fairings}

An image of the baseline tractor-trailer gap is shown in Figure 9. This geometry allows for flow between the underbody and the tractor-trailer gap region. The effect of sealing the bottom of the gap to vertical flow was investigated with the addition of full- and partial-width gap-floor plates (Fig. 10). The effect of the floor plates on the drag curves is shown in Figure 11. Relative to the baseline, both floor-plates provided reduced drag, especially for yaw angles between $\pm 5 \mathrm{deg}$ where cross flow is less important. At yaw angles between $\pm 2 \mathrm{deg}$, the partial floor plate was more effective than the full- width plate. At higher angles, the full-width floor plate was more effective. The resulting windaveraged drag reductions for the partial- and full gap-floor plates were 0.011 and 0.021 , respectively. These results indicate the benefit of blocking or reducing the vertical flow through the tractor-trailer gap.

\section{Trailer Underbody Fairings}

The effect of the trailer underbody detail was studied by covering the structural cross members with a simple flat-plate fairing that simulated a sandwich-type construction (Fig. 12). In addition, trailer side skirts were mounted on the underbody with a full-scale length and ground clearance of $4 \mathrm{~m}$ and $0.3 \mathrm{~m}$, respectively (Fig. 13). The effects of the smooth underbody and side skirts on the drag curves are presented in Figure 14. The smooth trailer underbody marginally reduced the drag at all yaw angles and yielded a wind-averaged drag reduction of 0.018 . Admittedly, the conversion of existing trailers to a smooth-underbody configuration is unpractical due to weight and cost considerations. However, if the floor of the trailer was designed to include a sandwich construction, these penalties could likely be avoided. The trailer side skirts were considerably more effective yielding a windaveraged drag reduction of 0.073 . This value is at the upper end of the range reported previously (Ref. 3) most probably due to the higher fidelity of the current underbody geometry. The combined effect of the tractor and trailer fairings was not measured.

\section{E. Surface Pressure Distributions}

Static surface pressures were measured on the back of the tractor, the front and back of the trailer, and on the side of the trailer. The pressure distributions along the vertical model centerline and on the left side of the trailer are presented in Figures 15-22 for selected configurations at yaw angles of 0 , 10 , and $-10 \mathrm{deg}$. In general, the same trends were observed for the off-centerline pressure-tap rows. The graphs are organized by location of the geometry modifications: 1) tractor fairing and gapfloor plates, and 2) smooth trailer underbody and trailer side skirts. Each graph includes the associated baseline for comparison. 
Due to internal structural details of the model tractor, only four pressure taps were installed along the vertical row at the model centerline. In addition, these taps are only on the lower two-thirds of the tractor base (the top of the trailer is at approximately $\mathrm{z} / \mathrm{w}=1.5$ ). The gap-floor plate produced the greatest change in the tractor pressure distributions (Fig. 15) by reducing the vertical gradient and associated vertical flow. Except at zero yaw, the tractor underbody fairing reduced the pressure on the tractor base (resulting in increased tractor drag). As expected the trailer modifications had little effect on the tractor pressure distributions (Fig. 16).

On the front of the trailer (Fig. 17), the effect of the height mismatch is observed as a relatively high pressure at pressure tap second from the top (near the region of flow stagnation on the trailer face). The gap-floor plate had the greatest effect at zero yaw where it significantly reduced pressures (and corresponding drag) over most of the trailer face. The tractor fairing resulted in only a margin decrease in pressure at zero yaw, and both modifications had a relatively small effect at \pm 10 deg. Again, the trailer modifications had little effect on the trailer-front pressure distributions (Fig. 18).

On the left side of the model, a row of pressure taps ran the length of the trailer at half-height. The pressure distributions indicate a minimal effect (mostly near the front) of the tractor fairing and gapfloor plate (Fig. 19). Relative to the baseline, the smooth trailer underbody and trailer side skirts generated marginally higher and lower pressures on the trailer side, respectively (Fig. 20).

On the base of the trailer, the effects of the tractor underbody fairing and gap-floor plate were marginal (Fig. 21). The effects of the trailer smooth underbody and side skirts, however, were significant. At zero yaw, both modifications provided a significant increase in pressure for the entire distribution. At \pm 10 deg yaw, the side skirts produced a greater pressure increase (and associated drag reduction) especially on the lower half of the base (Fig. 22). The difference between the pressure distributions of the smooth underbody and trailer skirts, however, is not enough to account for the significantly greater drag reduction of the side skirts. Apart from the increased base pressures, it should also be noted that the trailer side skirts effectively shield the rear boggies and trailer undercarriage, thereby reducing the drag on these underbody components.

\section{F. Estimated Fuel Savings}

The estimated annual fuel savings per truck was calculated using the methodology presented in Ref. 3 and assuming a typical use of $240,000 \mathrm{~km} / \mathrm{yr}$. For the configurations presented above, a summary of the measured wind-averaged drag reduction and estimated annual fuel savings is presented in Table 1. The smooth trailer underbody and side skirts yielded an estimated savings of 1653 and 6586 liters/yr. For the relatively small drag reduction of the smooth underbody configuration, the annual monetary savings for a 5,000 truck fleet (assuming a fuel cost of $\$ 0.83 /$ liter) would be close to $\$ 7$ million.

Table 1: Summary of drag reduction and estimated fuel savings per truck (based on $240,000 \mathrm{~km} / \mathrm{yr}$ ).

\begin{tabular}{|l|c|c|}
\hline Configuration & $\begin{array}{r}\text { Wind-avg } \\
\text { drag }\end{array}$ & $\begin{array}{r}\text { Fuel } \\
\text { savin }\end{array}$ \\
\hline Part Tractor & -0.015 & 1359 \\
\hline Full Tractor & -0.018 & 1635 \\
\hline Partial Floor Plate & -0.011 & 948 \\
\hline Full Floor Plate & -0.021 & 1912 \\
\hline Smooth Trailer & -0.018 & 1653 \\
\hline Trailer Side Skirts & -0.073 & 6586 \\
\hline
\end{tabular}

\section{Conclusions}

Experimental measurements were obtained of a 1:20-scale class-8 tractor-trailer model in the NASA-Ames 48- by 32-Inch Subsonic Wind Tunnel. Data were acquired at a Reynolds number of 430,000 for yaw angles between $\pm 14 \mathrm{deg}$. Forces, moments, and surface pressures were measured to detail a baseline configuration representative of a modern aero package with and without underbody and gap fairings.

Separate measurements of underbody fairings on the tractor and trailer yielded wind-averaged drag reduction of 0.018 for both configurations. A floor plate blocking vertical flow in the tractor-trailer gap resulted in a drag reduction of 0.021. Smaller fairings provided less benefit. As in previous 
studies, trailer side skirts proved to be the most effective trailer-underbody device, reducing the wind-averaged drag by 0.073 . An estimation of the annual fuel savings is provided for each configuration.

\section{References}

1. McCallen R., Flowers, D., Dunn, T., Owens, J., Leonard, A., Brady, M., Brownad, F., Hammache, M., Salari, K., Rutledge, W., Ross, J., Storms, B., Heineck, J.T., Driver, D., Bell, J., Zilliac, G., Walker, S., "Aerodynamic Drag of Heavy Vehicles (Class 7-8): Simulation and Benchmarking," 2000-012209, SAE Gov/Industry Meeting, Washington, D.C., June 19-21, 2000.

2. Cooper, K. R., "Truck Aerodynamics Reborn - Lessons from the Past," SAE Paper 200301-3376, November 2003.

3. Cooper, K., "The Wind Tunnel Testing of Heavy Trucks to Reduce Fuel Consumption," SAE Paper 821285, November 1982.

4. Croll, R. H., Gutierrez, W. T., Hassan, B., Suazo, J. E., and Riggins, A. J., "Experimental Investigation of the Ground Transportation Systems (GTS) Project for Heavy Vehicle Drag Reduction," SAE Paper 960907, February 1996.

5. Storms, B.L., Ross, J.C., Heineck, J.T., Walker, S.M., Driver, D.M. and Zilliac, G.G., "An Experimental Study of the Ground Transportation System (GTS) Model in the NASA Ames 7- by 10-Foot Wind Tunnel." NASA/TM-2001-209621, February 2001.

6. Hammache, M., Michaelian, M., and Browand, F. "Aerodynamic Forces on Truck Models, Including Two Trucks in Tandem," SAE Paper 2002-01-0530, March 2002.

7. Heineck, J. T., Walker, S. M., and Satran, D., "The Measurement of Wake and Gap Flows of the Generic Conventional Truck Model (GCM) using Three-Component PIV," The Aerodynamics of Heavy Vehicles: Trucks, Buses and Trains, Monterey-Pacific Grove, CA, Dec. 2002.

8. Storms, B. L., Satran, D. R., Heineck, J. T., and Walker, S. M., "A Study of Reynolds Number Effects and Drag-Reduction Concepts on a Generic Tractor-Trailer," AIAA Paper 2004-2251, June 2004.
9. "SAE Wind Tunnel Test Procedure for Trucks and Buses," SAE J1252 JUL81, SAE Recommended Practice, July 1981.

10. Cooper, K. R and Leuschen, J., "Model and Full-Scale Wind Tunnel Tests of SecondGeneration Aerodynamic Fuel Saving Devices for Tractor-Trailers," SAE Paper 2005-013512, November 2005.

\section{Nomenclature}

$$
\begin{array}{ll}
A & =\text { tractor-trailer frontal area }=\mathrm{w}^{*} \mathrm{~h} \\
C_{D} & =\text { body-axis drag coefficient }=\mathrm{D} / \mathrm{q}^{*} \mathrm{~A} \\
\bar{C}_{D} & =\text { wind-averaged drag coefficient } \\
D & =\text { body-axis drag } \\
q & =\text { test-section dynamic pressure }=1 / 2 \rho \mathrm{U}^{2} \\
R e & =\text { Reynolds number }=\mathrm{U}^{*} \mathrm{~W} / \mathrm{v} \\
\mathrm{U} & =\text { free-stream velocity } \\
\mathrm{w} & =\text { truck width } \\
\mathrm{X} & =\text { axial distance from front bumper } \\
\mathrm{y} & =\text { lateral distance from model centerline } \\
\mathrm{Z} & =\text { vertical distance from bottom of bumper } \\
v & =\text { kinematic viscosity } \\
\rho & =\text { air density } \\
\psi & =\text { yaw angle (positive nose right) }
\end{array}
$$




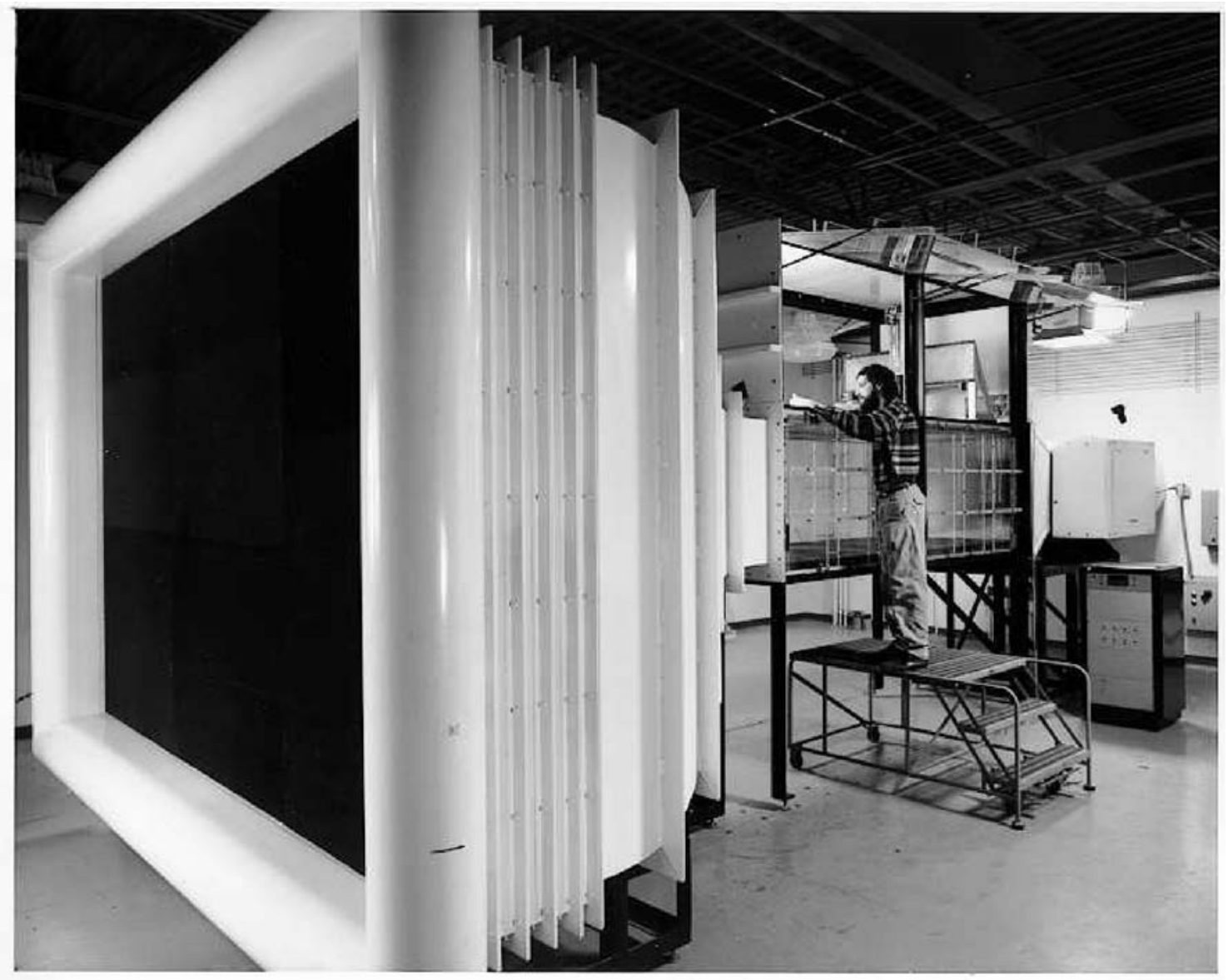

Figure 1: NASA Ames 48- by 32-Inch Subsonic Wind Tunnel (Inlet at left, plenum chamber above with doors open, test section below).
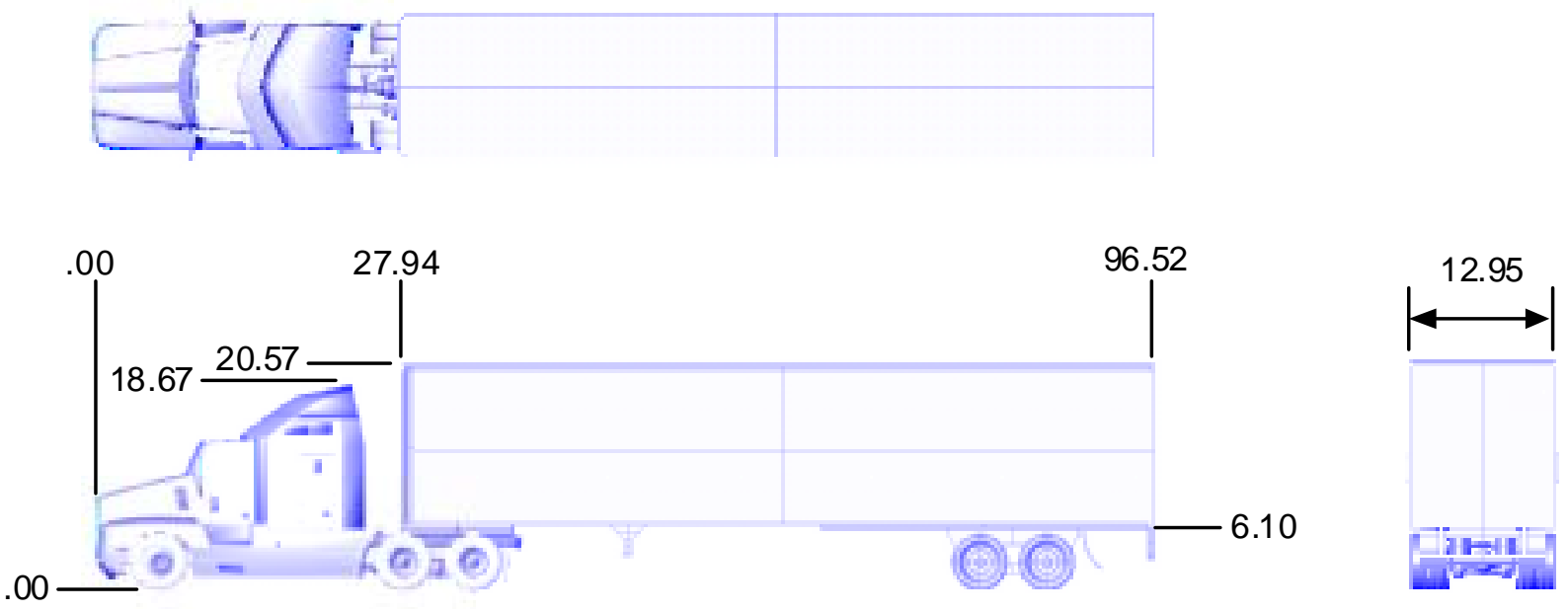

Figure 2: Three-view drawing of baseline tractor-trailer configuration (measurements in $\mathrm{cm}$ ). Note height mismatch between tractor and trailer due to inaccuracies in the publicly available CAD geometry. 


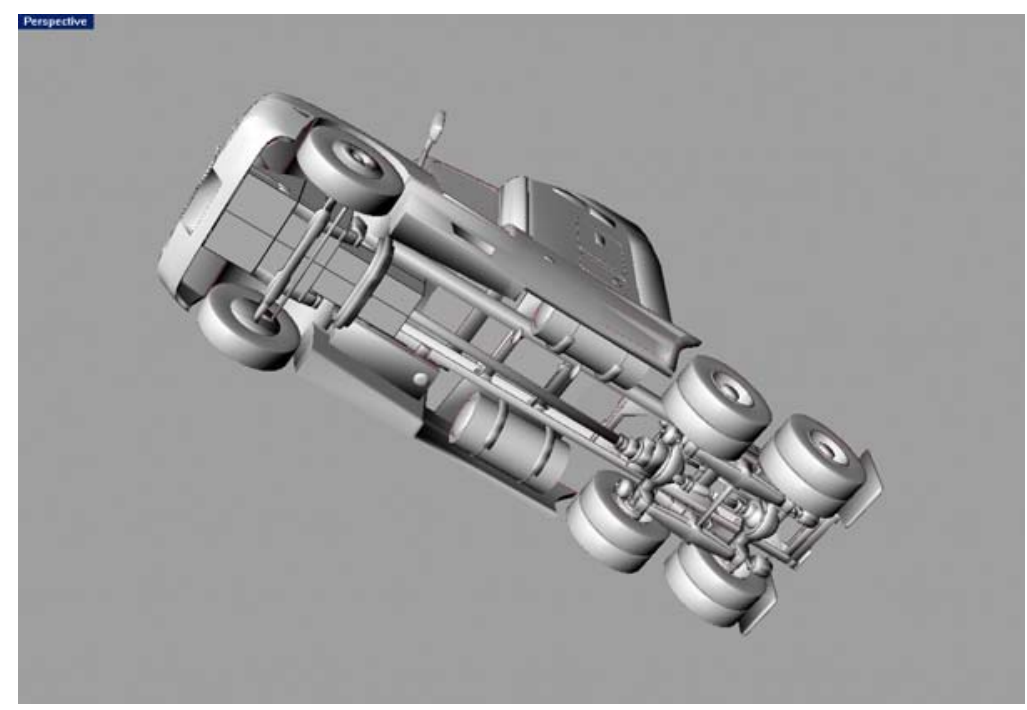

Figure 3: View of tractor underbody detail including simplified engine block.

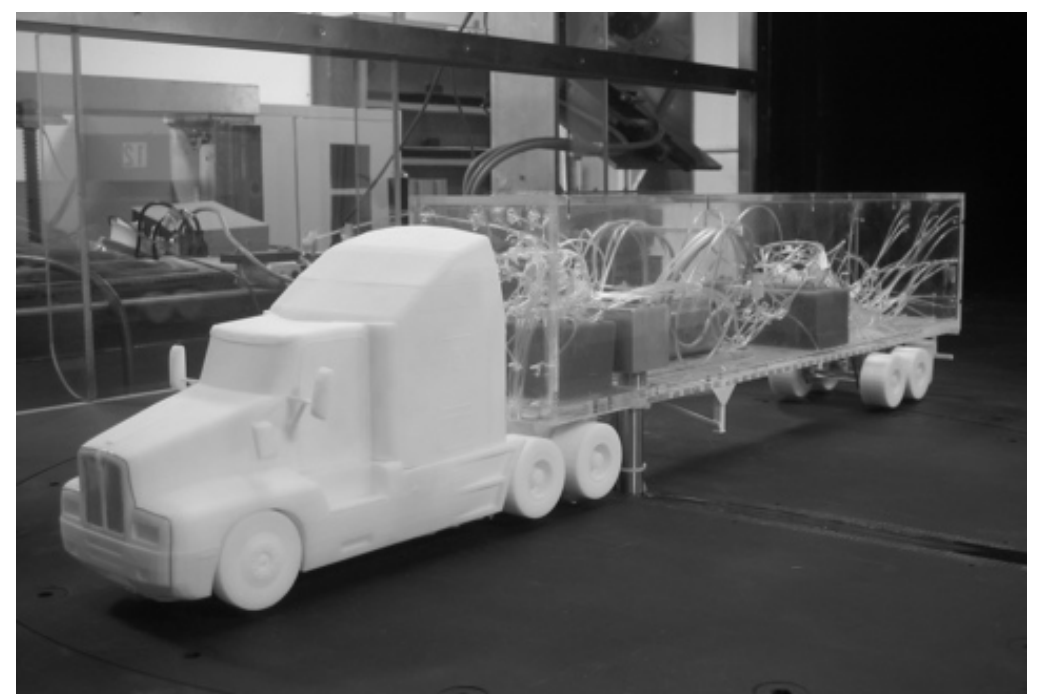

Figure 4: 1:20-scale model installed in the 48- by 32-Inch Wind Tunnel test section. The trip wire is visible as a dark line at the front of the tractor. 


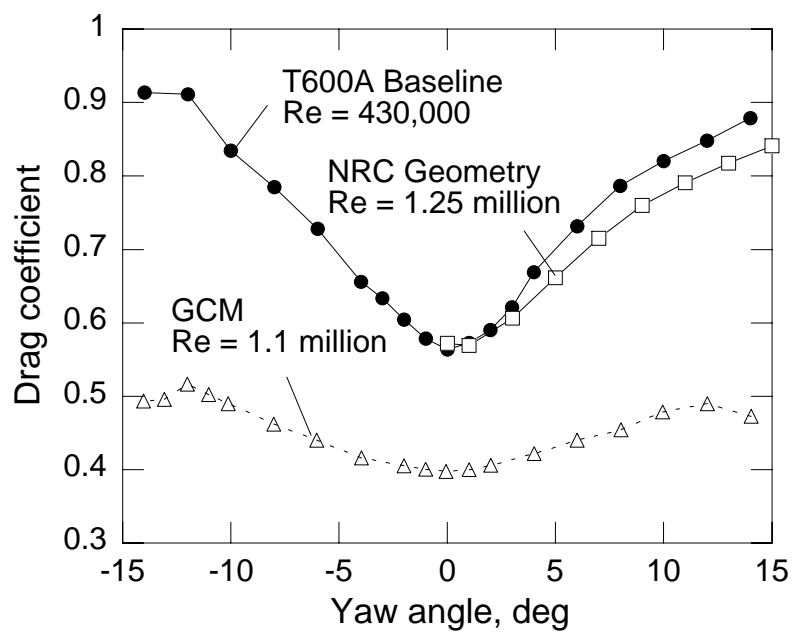

Figure 5: Drag curves of current and previous configurations. repeats.

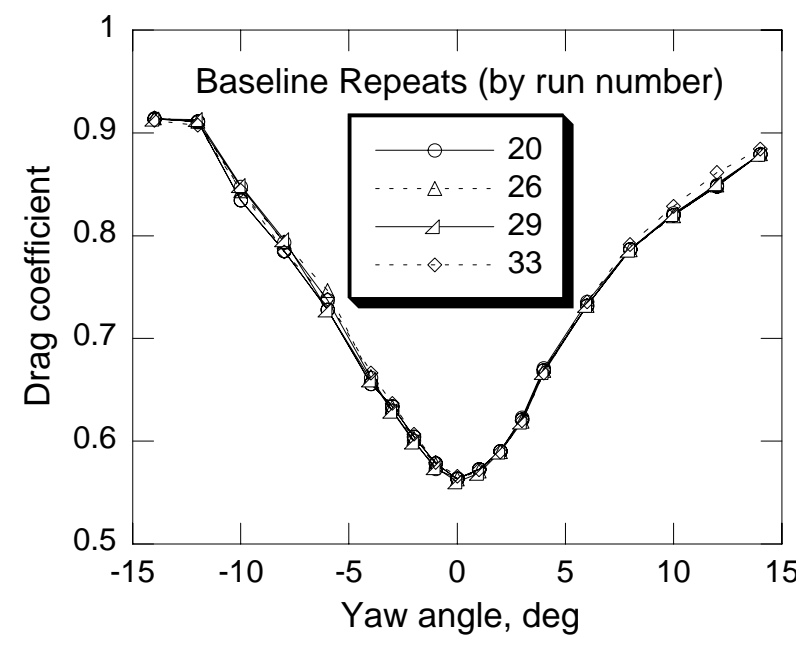

Figure 6: Drag curves for baseline
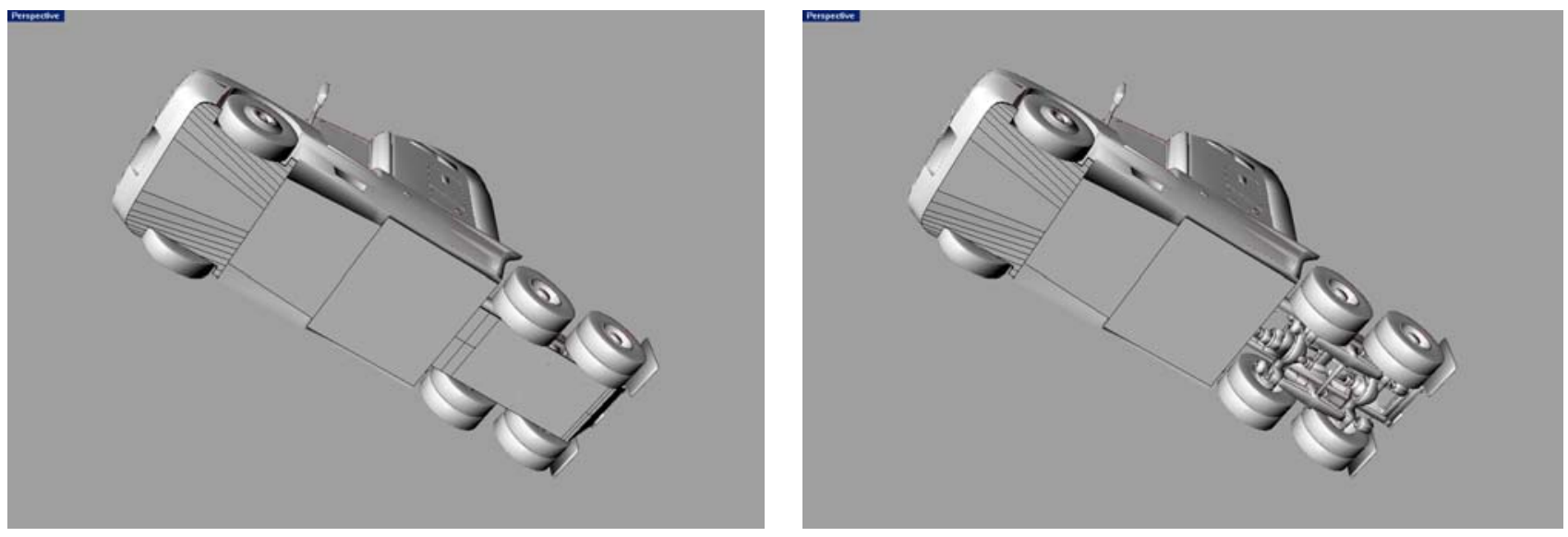

Figure 7: Full and partial underbody fairings on the tractor.

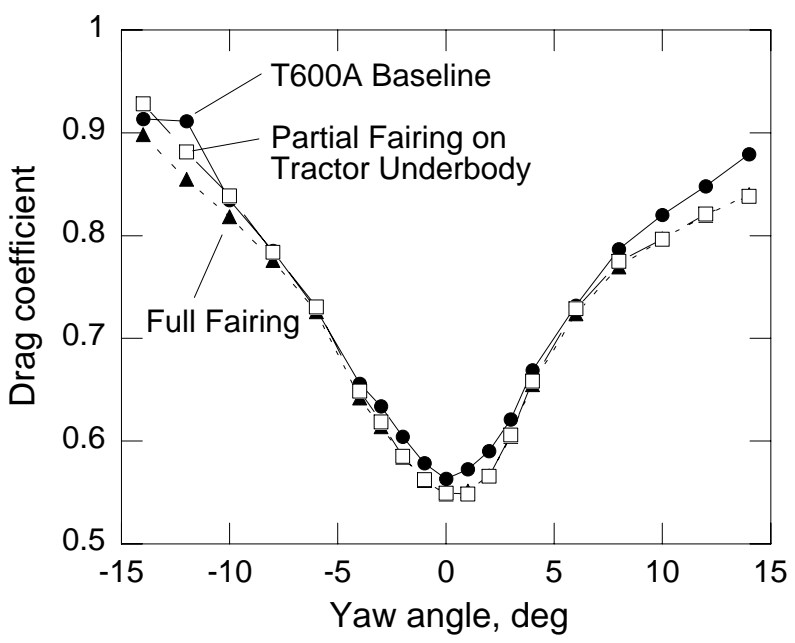


Figure 8: Effect of tractor underbody fairings on drag curve.

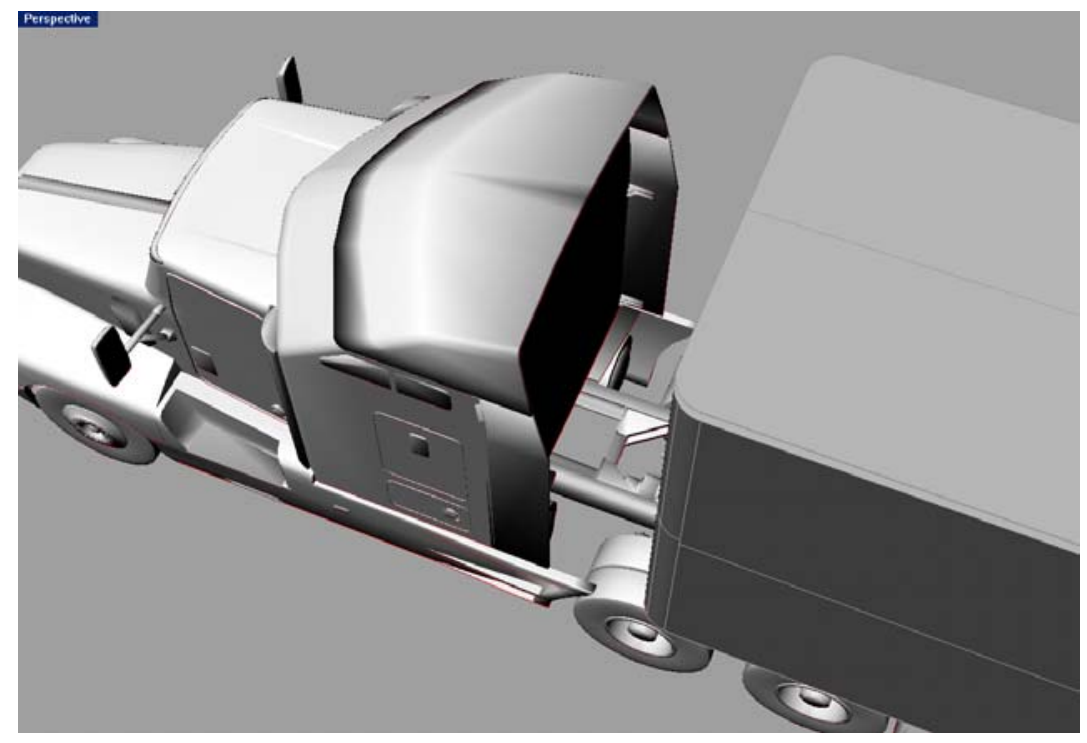

Figure 9: View of tractor-trailer gap (tractor-trailer separation $=1 \mathrm{~m}$ full-scale).
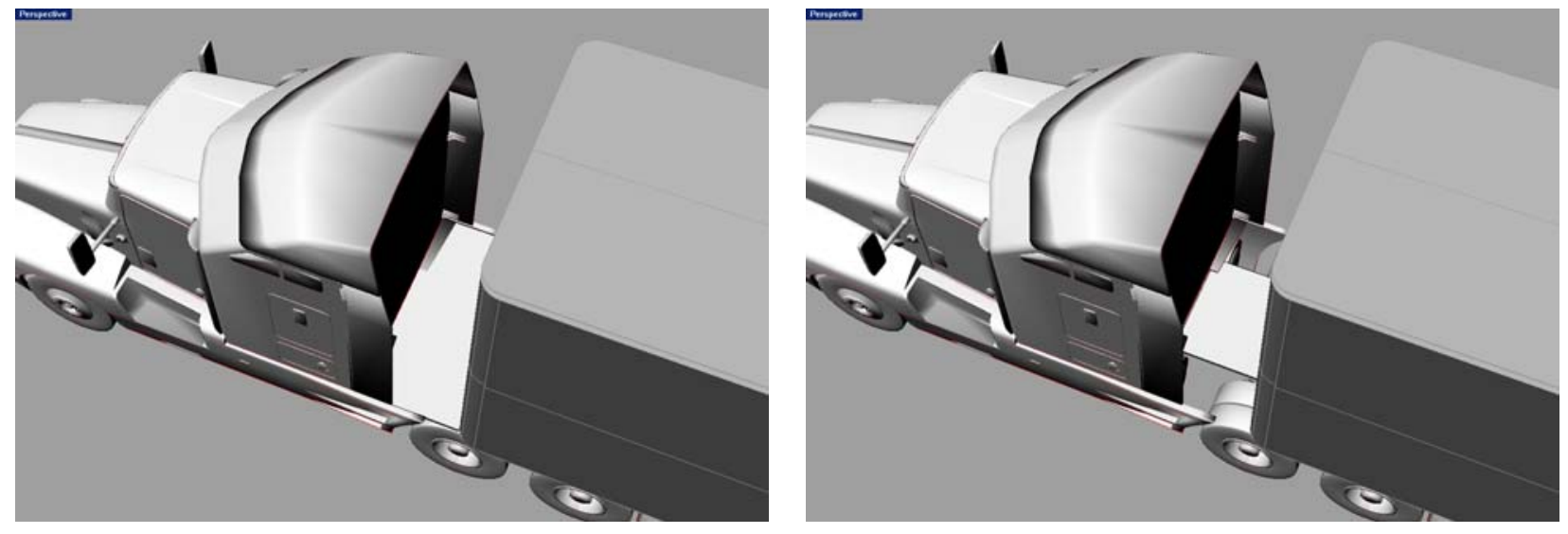

Figure 10: Full and partial floor plates in the tractor-trailer gap. 


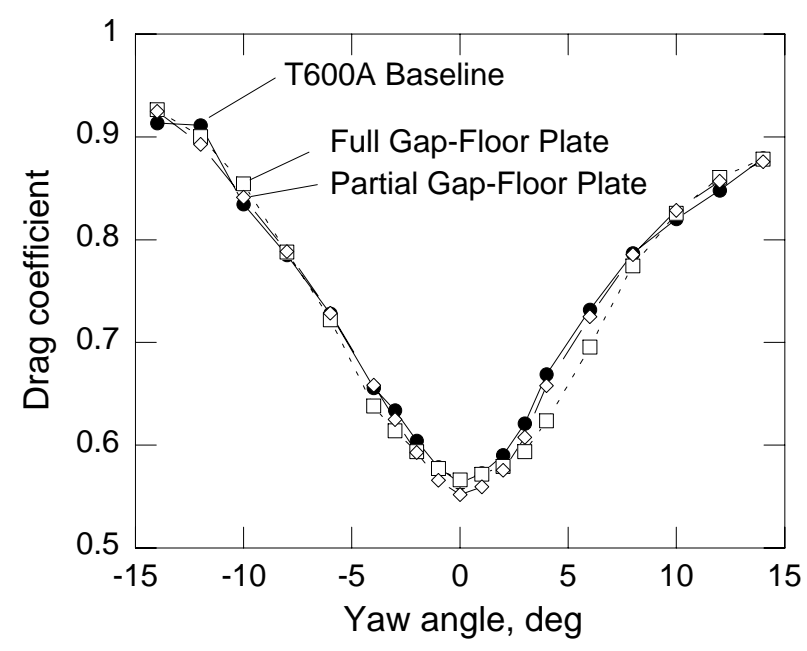

Figure 11: Effect of tractor-trailer gap-floor plates on drag curve.
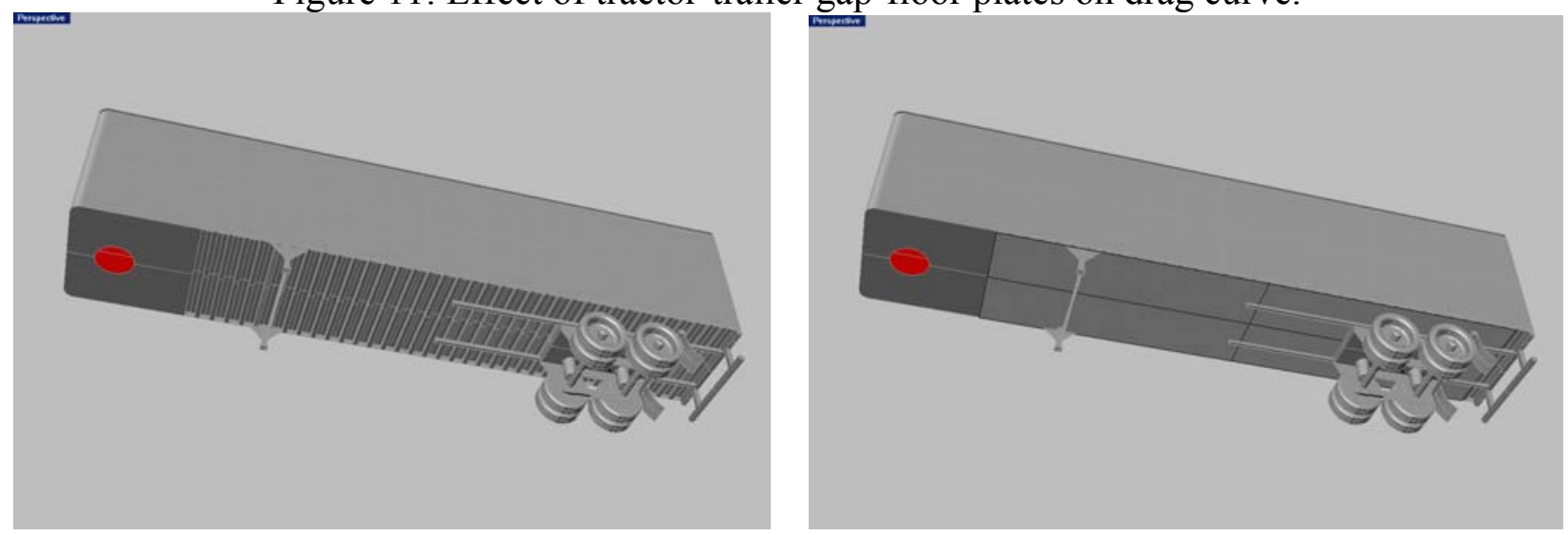

Figure 12: Trailer underbody with and without simple fairing.

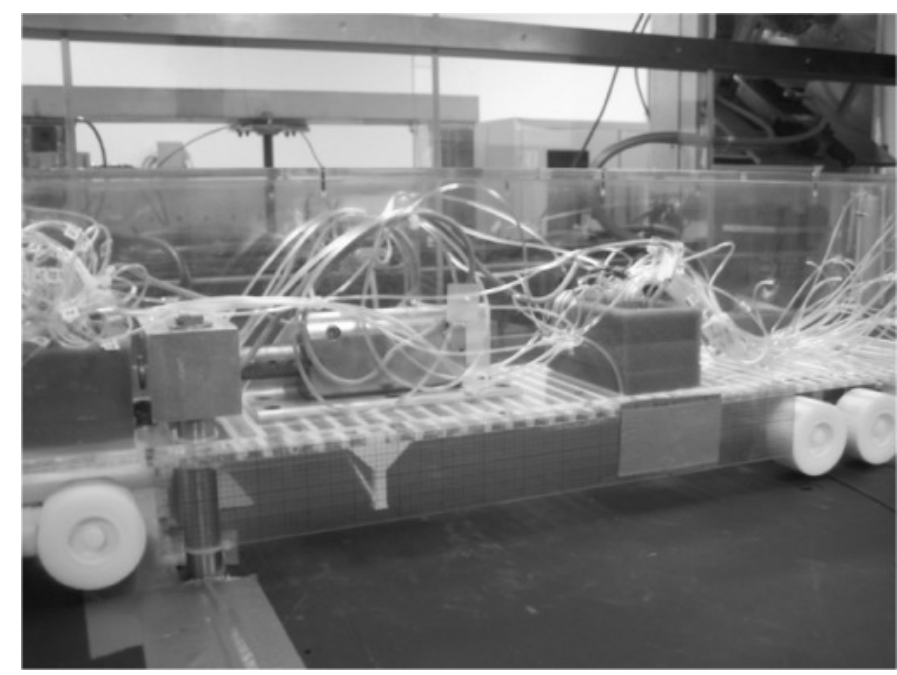

Figure 13: Trailer side skirts mounted on trailer underbody. 


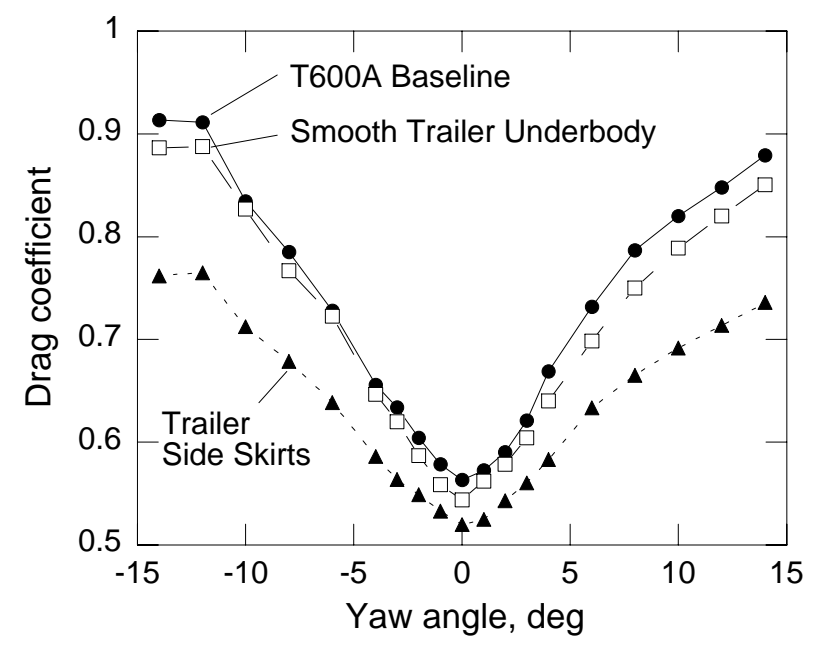

Figure 14: Effect of smooth trailer underbody and side skirts on drag curve.

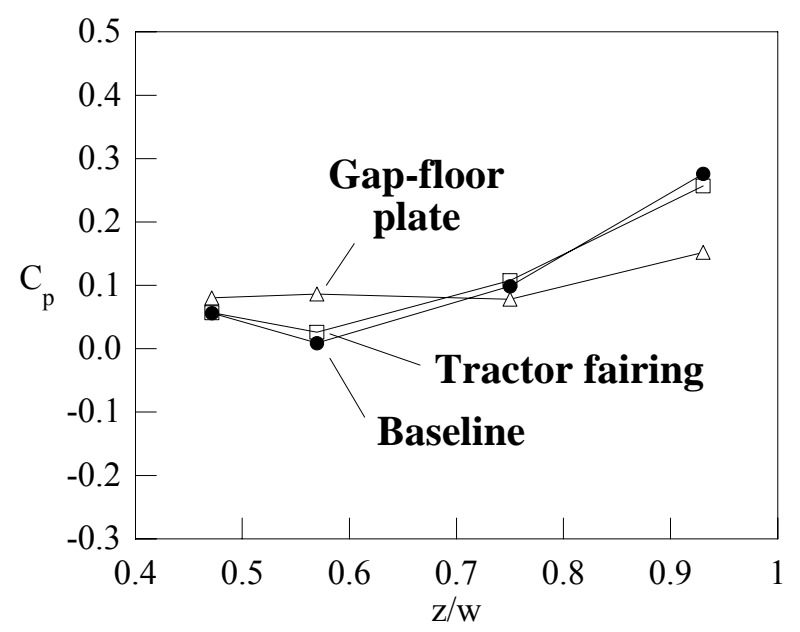

a) $\Psi=0^{\circ}$

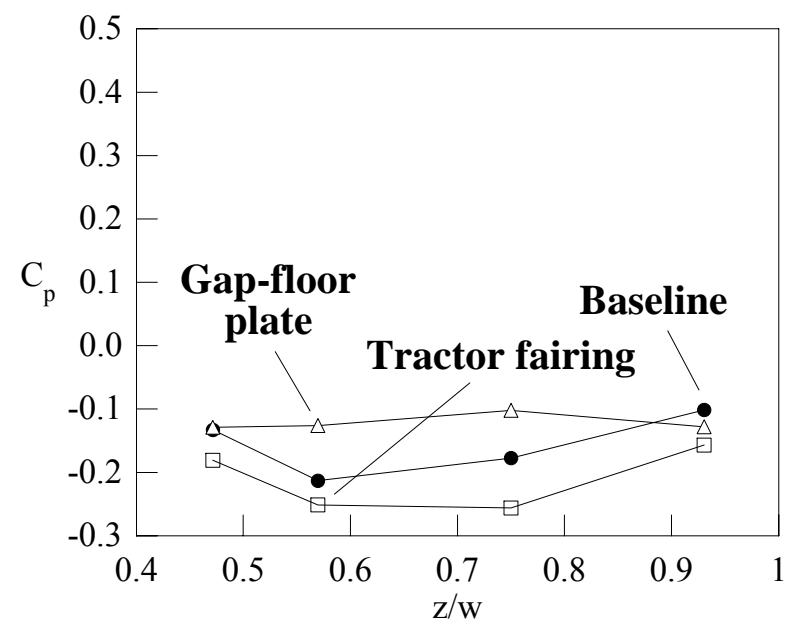

b) $\Psi=10^{\circ}$ 
FY 2006 Annual Report

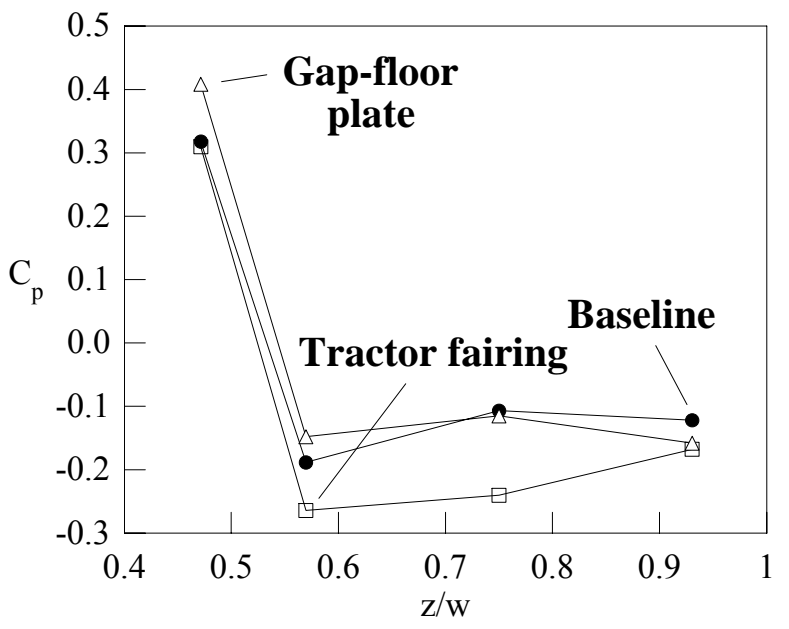

c) $\Psi=-10^{\circ}$

Figure 15: Effect of full trailer fairing and gap-floor plate on tractor-base centerline pressure coefficients.

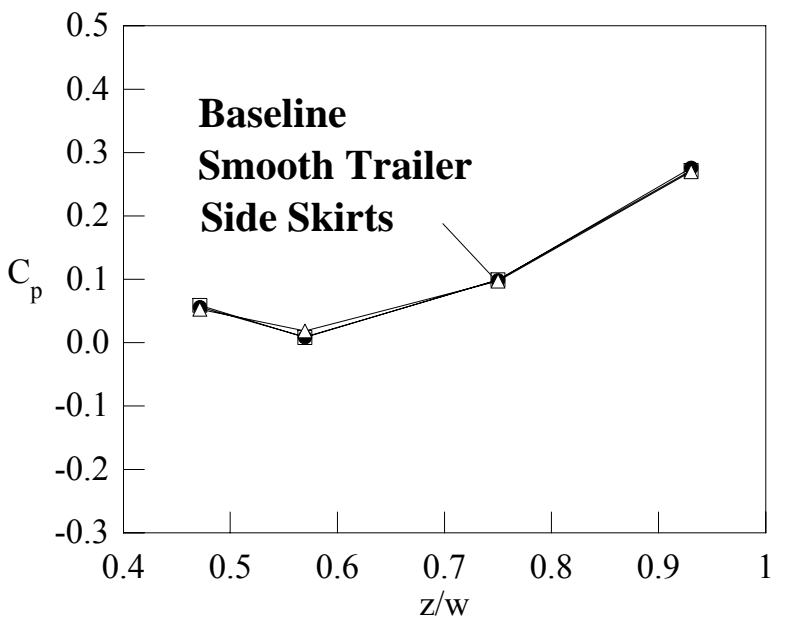

a) $\Psi=0^{\circ}$

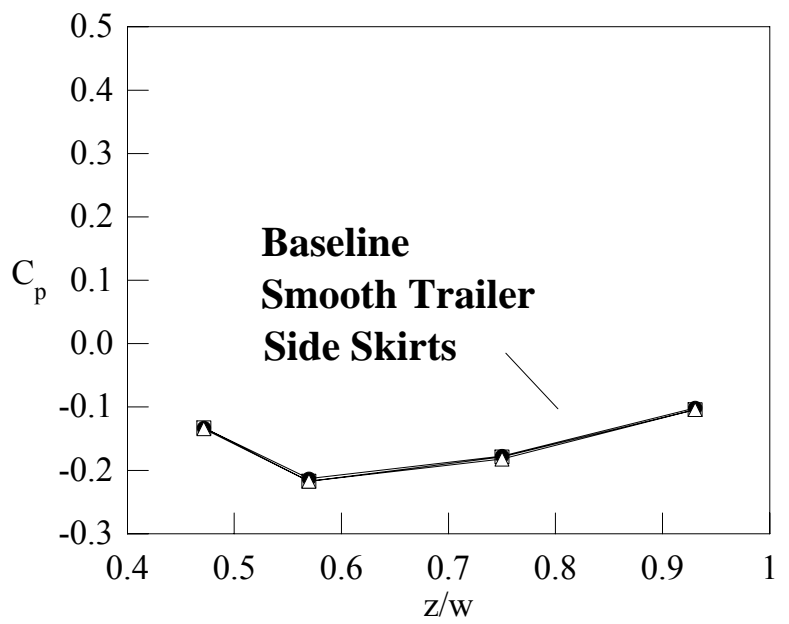


FY 2006 Annual Report

b) $\Psi=10^{\circ}$

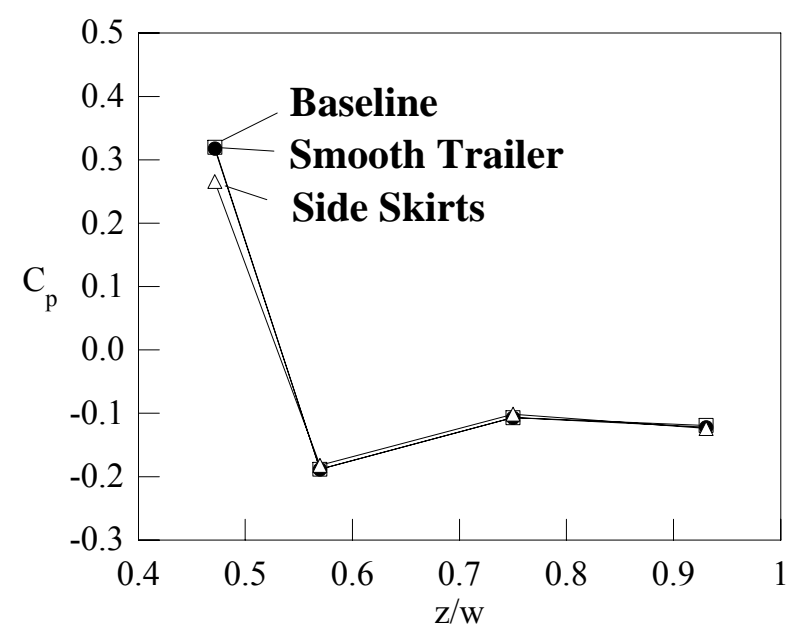

c) $\Psi=-10^{\circ}$

Figure 16: Effect of smooth trailer underbody and side skirts on tractor-base centerline pressure coefficients.

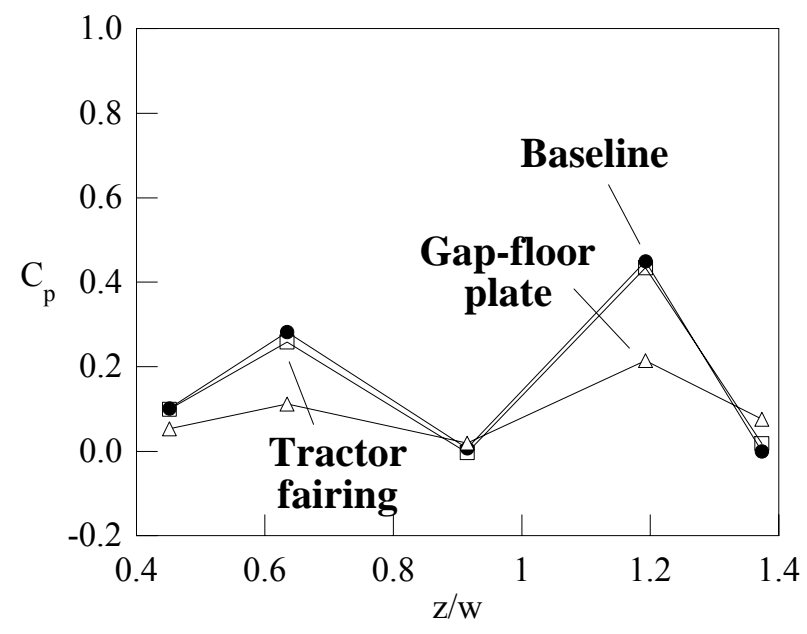

a) $\Psi=0^{\circ}$ 
FY 2006 Annual Report

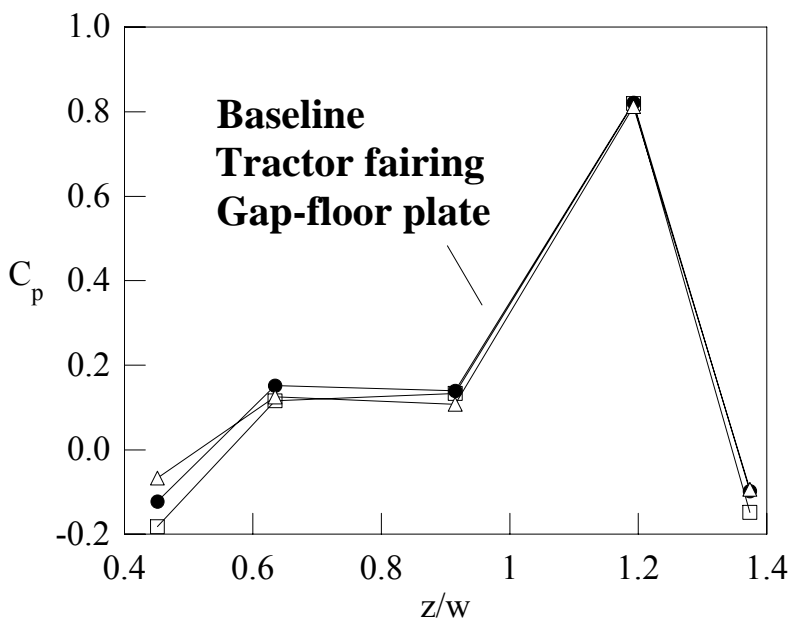

b) $\Psi=10^{\circ}$

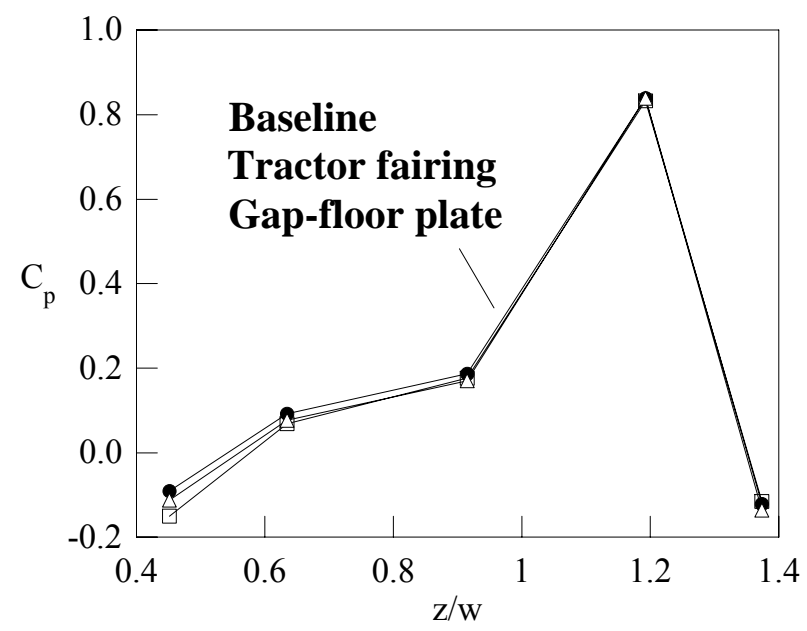

c) $\Psi=-10^{\circ}$

Figure 17: Effect of full trailer fairing and gap-floor plate on trailer-front centerline pressure coefficients.

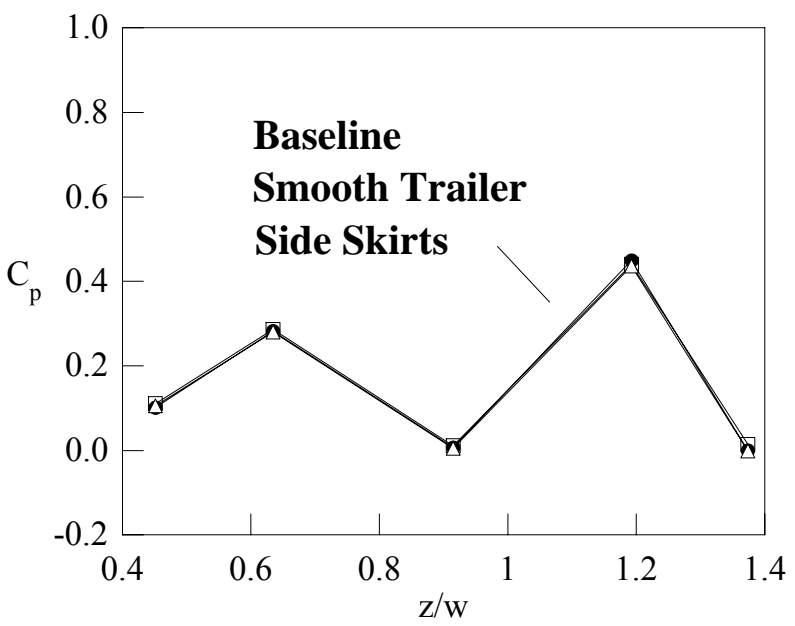


FY 2006 Annual Report

a) $\Psi=0^{\circ}$

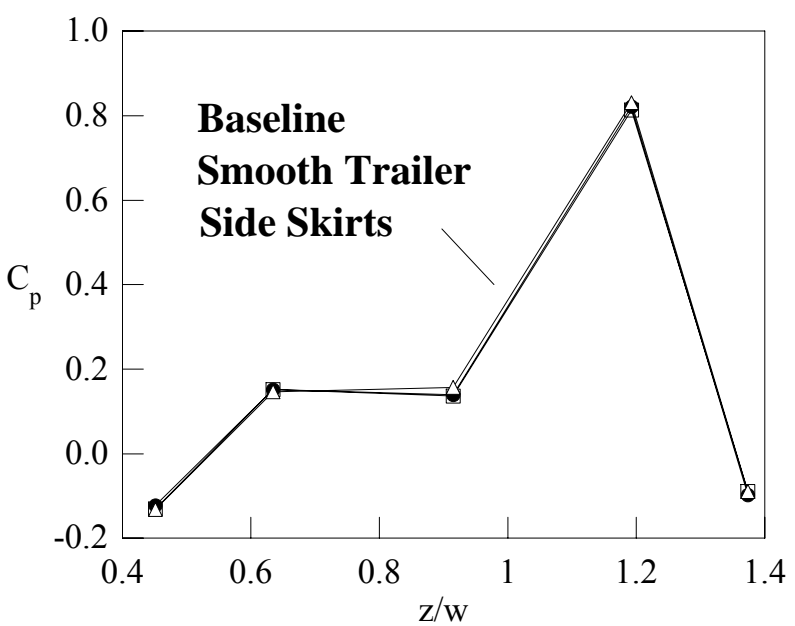

b) $\Psi=10^{\circ}$

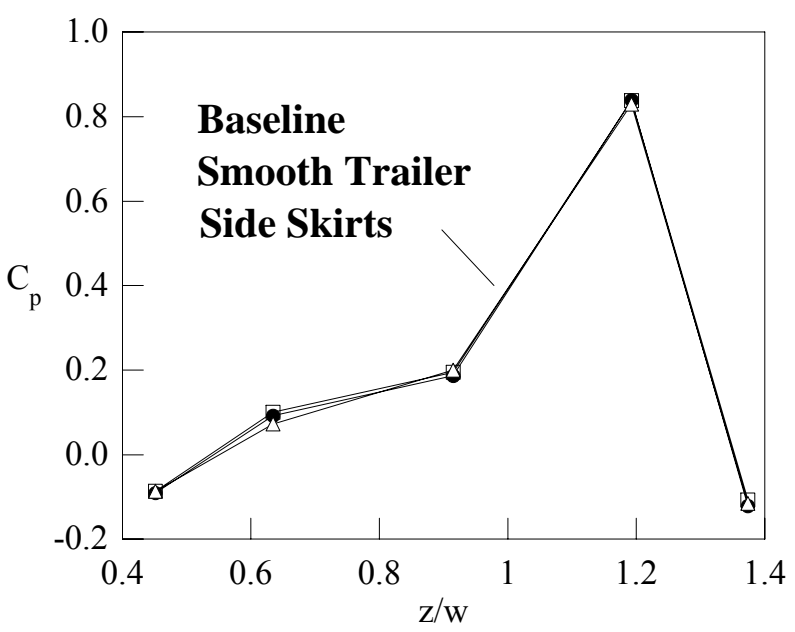

c) $\Psi=-10^{\circ}$

Figure 18: Effect of smooth trailer underbody and side skirts on trailer-front centerline pressure coefficients. 
FY 2006 Annual Report

Heavy Vehicle Aerodynamics

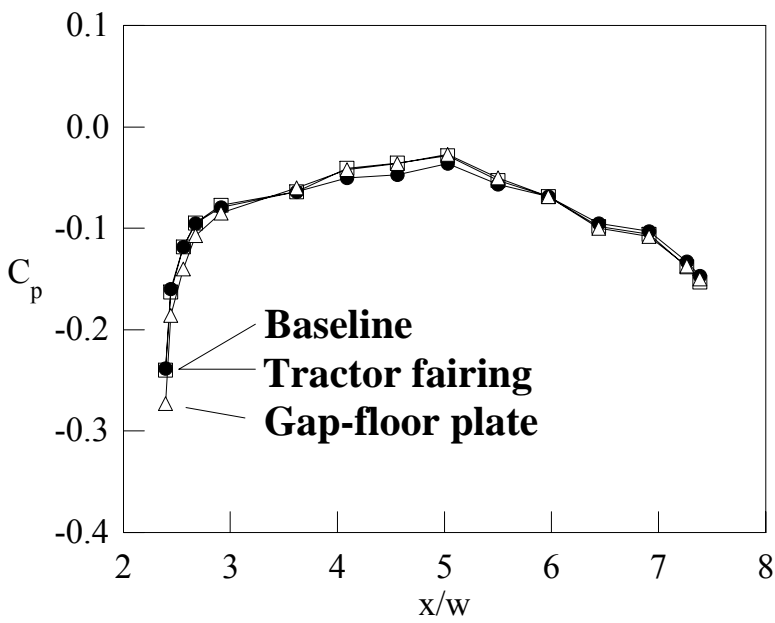

a) $\Psi=0^{\circ}$

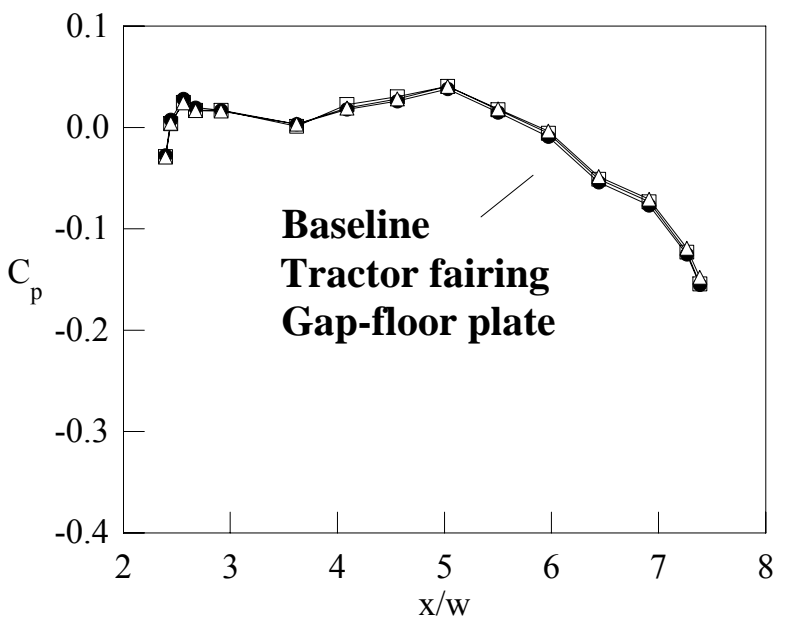

c) $\Psi=10^{\circ}$

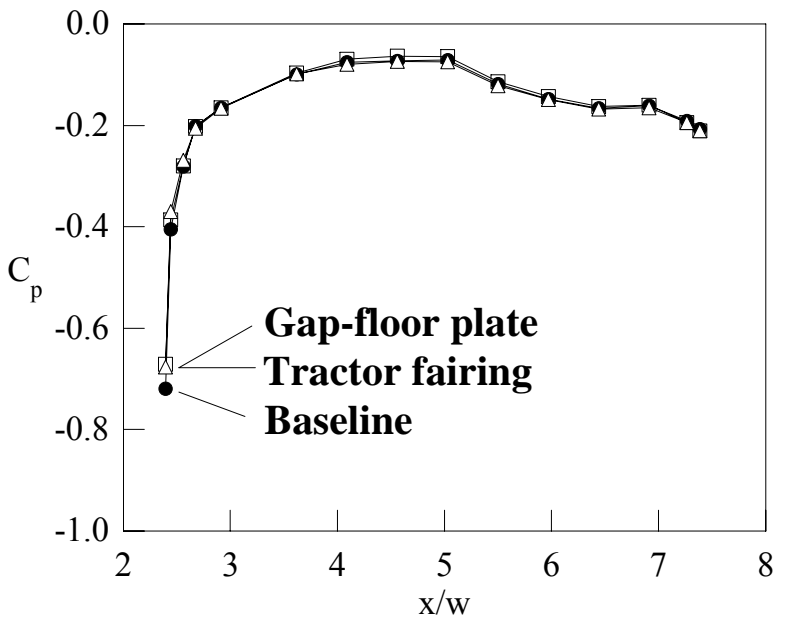

c) $\Psi=-10^{\circ}$ 
Figure 19: Effect of full trailer fairing and gap-floor plate on trailer left-side centerline pressure coefficients.

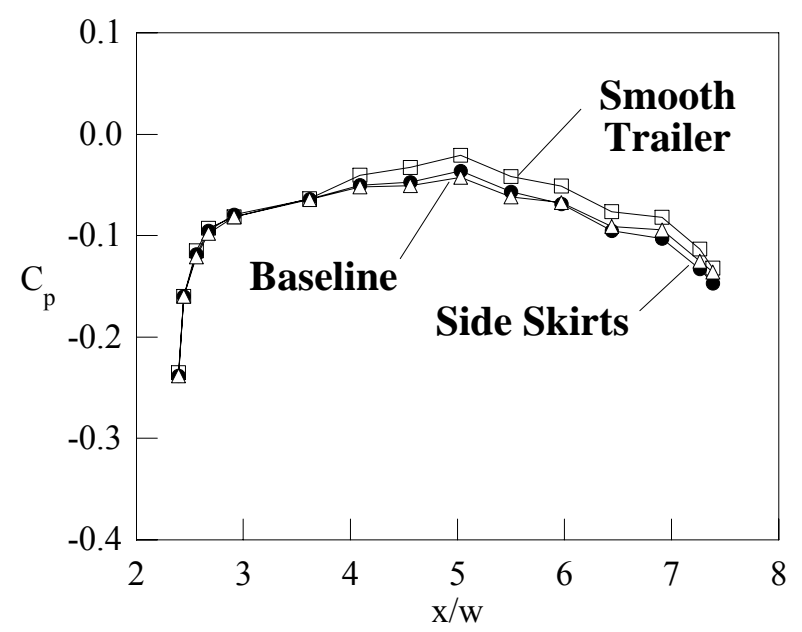

a) $\Psi=0^{\circ}$

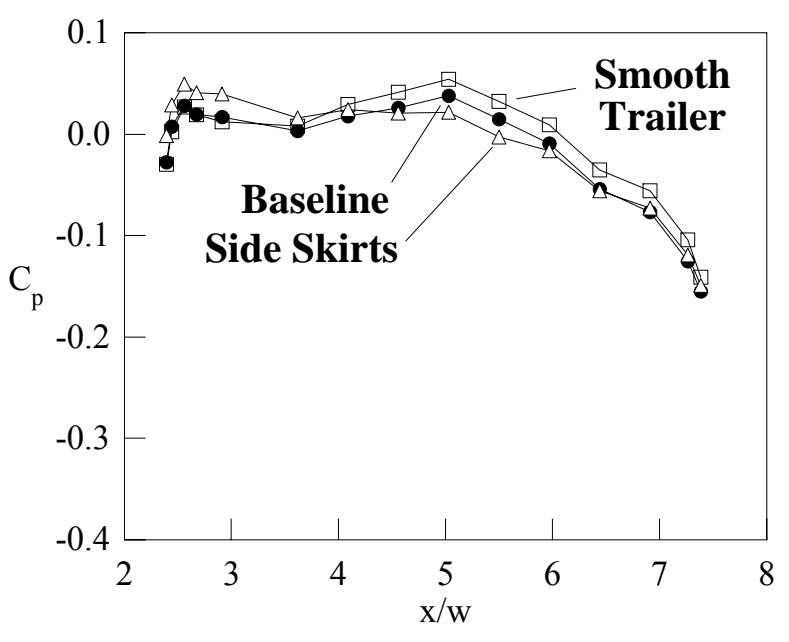

c) $\Psi=10^{\circ}$

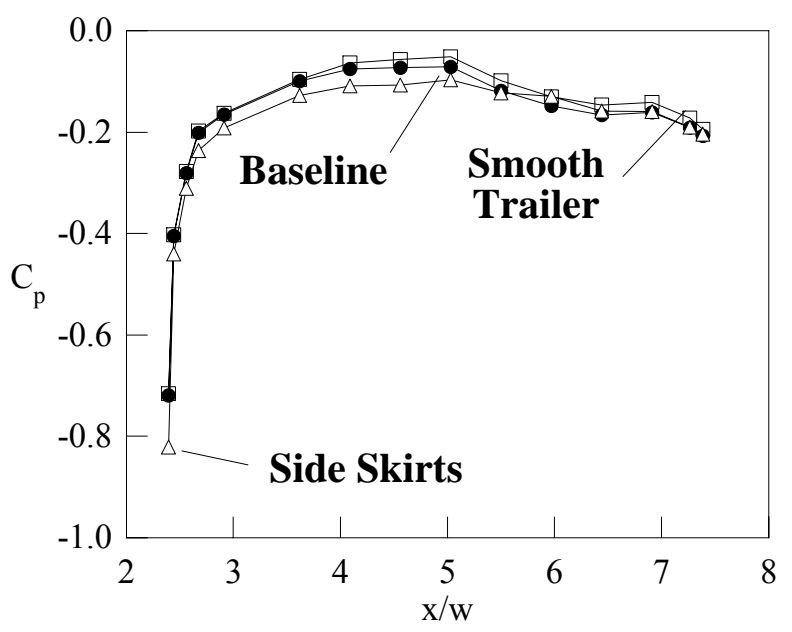


FY 2006 Annual Report
c) $\Psi=-10^{\circ}$

Figure 20: Effect of smooth trailer underbody and side skirts on trailer left-side centerline pressure coefficients.

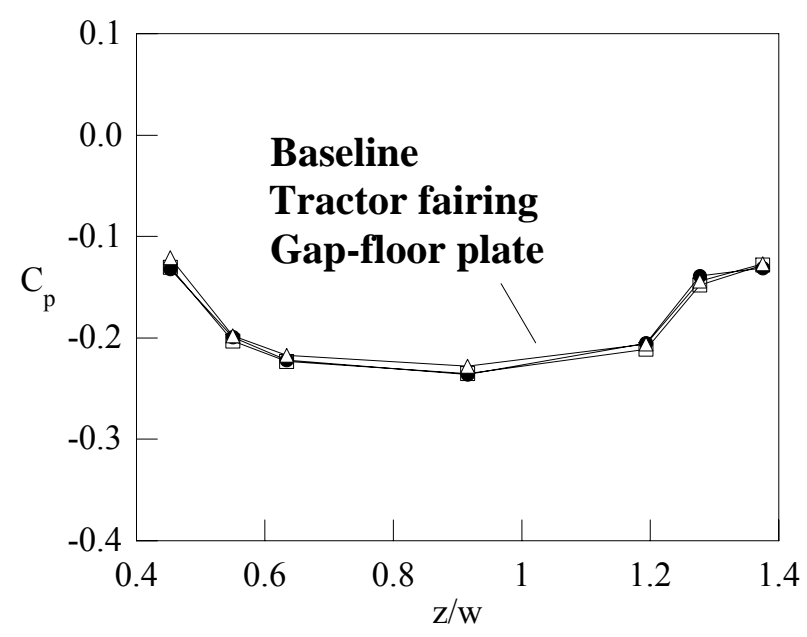

a) $\Psi=0^{\circ}$

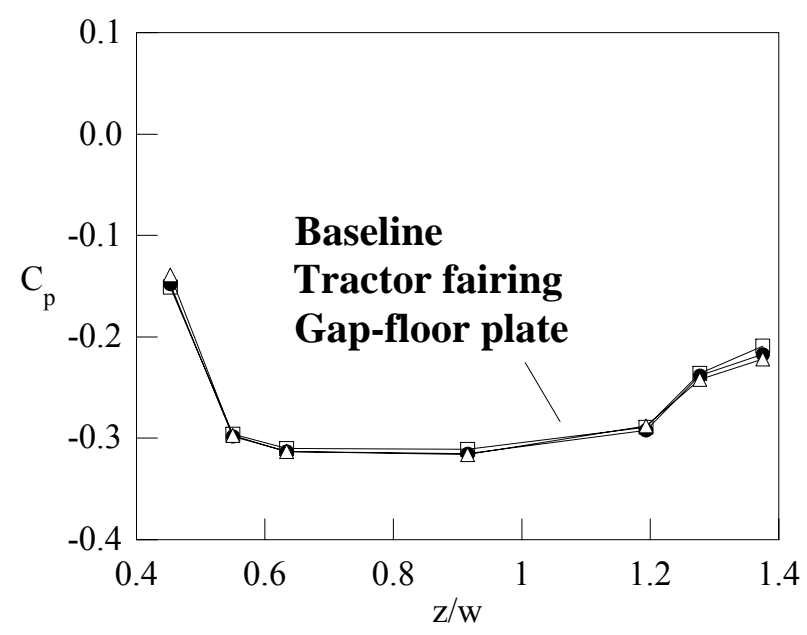

b) $\Psi=10^{\circ}$ 
FY 2006 Annual Report

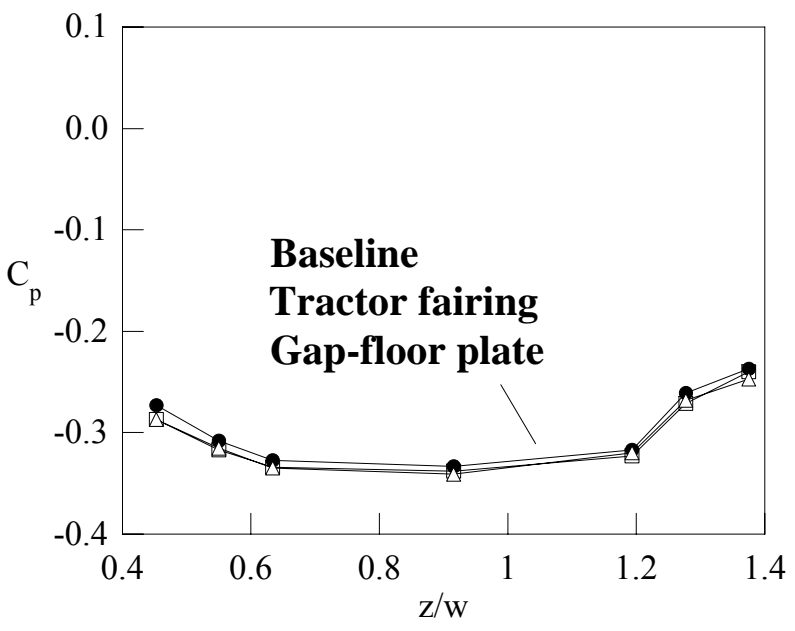

c) $\Psi=-10^{\circ}$

Figure 21: Effect of full trailer fairing and gap-floor plate on trailer-base centerline pressure coefficients.

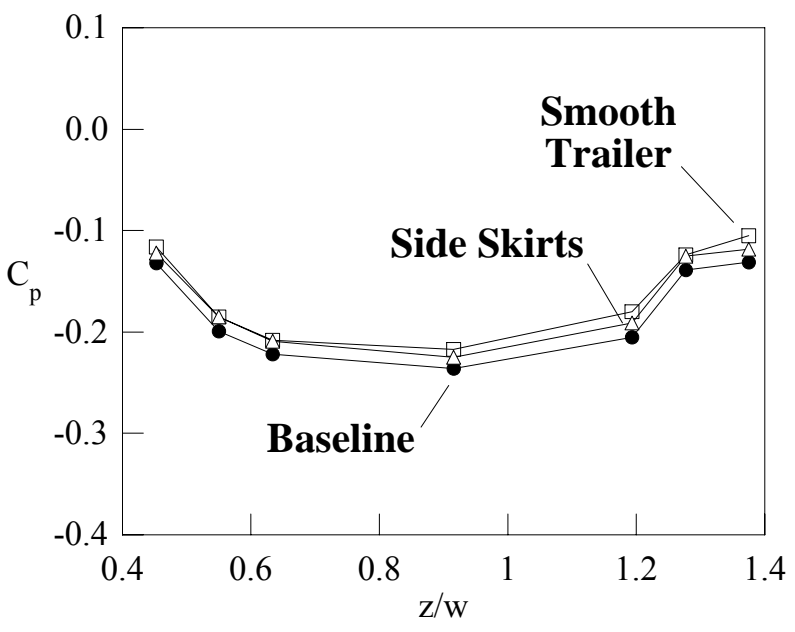

a) $\Psi=0^{\circ}$

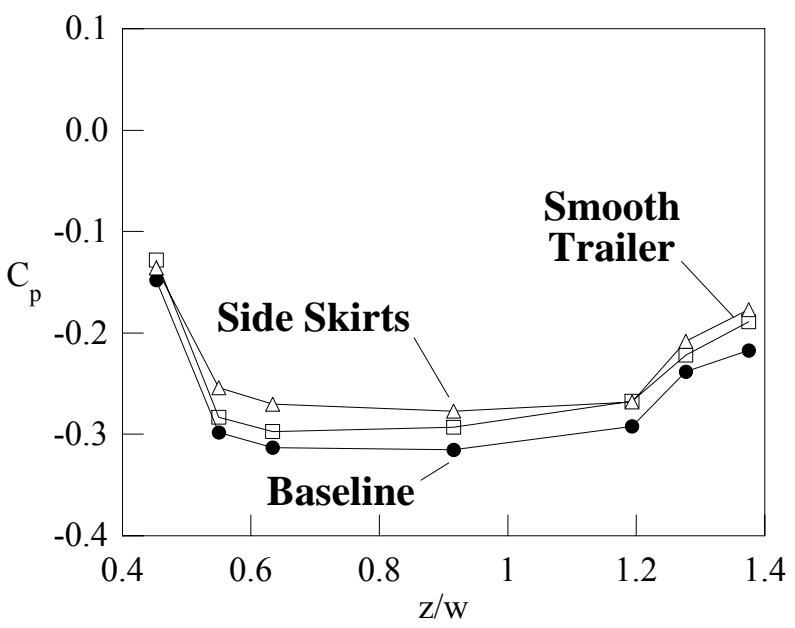


b) $\Psi=10^{\circ}$

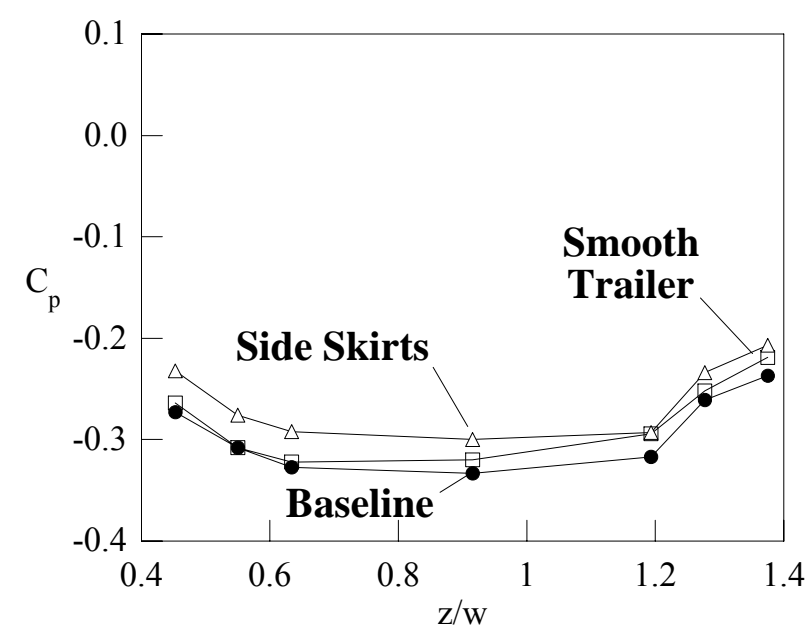

c) $\Psi=-10^{\circ}$

Figure 22: Effect of smooth trailer underbody and side skirts on trailer-base centerline pressure coefficients. 


\title{
APPENDIX D
}

\section{Commercial CFD Code Validation for External Aerodynamics Simulations of Realistic Heavy-Vehicle Configurations}

\author{
W. David Pointer, J. Chang, S. Singh, E. Dringenberg \\ Argonne National Laboratory \\ 9700 S Cass Avenue, NE-208, Argonne, IL 60439 \\ (630)252-1052; fax: (630)252-4500; email:dpointer@anl.gov \\ Technology Development Manager: Lee Slezak \\ 202-586-2335, Lee.Slezak@EE.DOE.GOV \\ Technical Program Manager: Jules Routbort \\ 630-252-5065,routbort@anl.gov
}

Contractor: Argonne National Laboratory

Contract No.: W-31-109-ENG-38

\section{Objective}

- Evaluate capabilities in standard commercial computational fluid dynamics (CFD) software for the prediction of aerodynamic characteristics of a conventional U.S. Class 8 tractor-trailer truck.

- Develop practices and procedures for the application of commercial CFD software in the design process of Class 8 vehicles.

- Apply practices and procedures to evaluation of geometric modifications and drag-reducing devices to assess potential energy savings

\section{Approach}

- Develop computational models of simplified vehicles based on the Generic Convention Model geometry used in experiments completed in the NASA Ames Laboratory's $7 \mathrm{ft}$. by $10 \mathrm{ft}$. wind tunnel.

- Compare the predictions of the computational models with experimental measurements of vehicle aerodynamic drag force and pressure field distributions.

\section{Accomplishments}

- Experimental measurements and computational predictions of the vehicle drag coefficient agree within less than 1 percent in the best case simulations at zero yaw and within less than 5\% at higher yaw angles. Experimental measurements and computational predictions of the pressure distribution along the surface of the vehicle agree well everywhere except the rear faces of the cab and the trailer.

- Confirmed applicability of the practices and procedures to the evaluation of devices which modify the wake flow at the rear of the trailer.

- Confirmed difficulty in applying this methodology to configurations which result in a significant increase in the relative importance of the base drag acting on the rear faces of the trailer.

- Established that small changes in radiator width or height do not significantly impact the drag coefficient if all other dimensions are held constant. 
- Established that the flow into the underhood through the radiator does not significantly impact the drag losses.

\title{
Future Direction
}

- Work with team members in the development of an integrated approach to development of the next generation heavy vehicle transportation

\begin{abstract}
With rising oil prices, the issue of energy economy in transportation is getting much attention. At the same time, new emissions standards for tractor-trailer vehicles introduce additional challenges for the manufacturers to achieve improvements in vehicle fuel economy. As part of the U.S. Department of Energy Office of FreedomCAR and Vehicle Technologies' Heavy Vehicle Aerodynamic Drag Consortium, Argonne National Laboratory is applying commercial computational fluid dynamics (CFD) software to facilitate energy efficiency improvements through improved aerodynamic design of tractor-trailer vehicles. Early investigations sought to establish the validity of this approach by evaluating the sensitivity of the predictions of drag coefficients and surface pressure distributions for the standard configuration of the GCM to the size and structure of the computational mesh and the selection of turbulence model. Current assessments are focusing on the ability to predict the change in the drag coefficient when drag reduction devices are employed and the application of the code to design studies.
\end{abstract}

\section{MODELING STRATEGY}

This program has provided guidance for the use of commercial CFD software in heavy vehicle design, including the expected impact of grid resolution and structure on prediction accuracy, the impact of the RANS turbulence model formulation selected, the impact of considering only half of a vehicle to speed up initial simulations. The experience developed by this program provides generic advice for the application of a commercial CFD software package to the prediction of heavy vehicle aerodynamic drag coefficients. Since this market is currently dominated by finite volume formulations, the guidelines will focus upon software using this methodology.

\section{Selection of Commercial CFD Software}

All simulations completed as part of this program have used the commercial CFD code Star-CD. ${ }^{1}$ The Star-CD software was selected for this purpose largely the code offers a great deal of the flexibility in computational mesh development with the ability to utilize polyhedral "cut" cells and recognize both integral and arbitrary interfaces between regions of the computational domain. Furthermore, user subroutines allow the user to implement significant modifications to most features of the code if such modifications are needed. It is anticipated that the applicability of the general observations on modeling strategy extends to other commercial CFD codes using the finite volume methodology.

\subsection{SELECTION OF TRACTOR TRAILER GEOMETRY}

The Generic Conventional Model $^{1}$ (GCM), developed by NASA Ames Research Center for scaled wind tunnel testing, is a generalized representation of a conventional U.S. tractor-trailer truck, as shown in Figure 1. The 1/8th scale model is approximately $2.5 \mathrm{~m}$ long by $0.3 \mathrm{~m}$ wide by $0.5 \mathrm{~m}$ high. The studies contained herein consider experiments that were completed in the NASA Ames $7 \mathrm{ft}$. by $10 \mathrm{ft}$. wind tunnel. Instrumentation included a force balance, 476 steady pressure transducers, 14 dynamic pressure transducers, and three-dimensional Particle Image Velocimetry (PIV). Data was collected at various Reynolds number values and yaw angles. The initial studies presented herein consider only the case using the standard configuration of the GCM with a vehicle-width based Reynolds number of $\operatorname{Re}=1.15$ million. Measurements using alternate configurations with add on devices will be used to evaluate whether computational modeling guidelines developed based upon these studies are sufficiently general to be applied in the evaluation of the aerodynamic characteristics of other vehicles under different operating conditions.

\subsection{COMPUTATIONAL MODEL}

The computational model employed in these studies was developed using the ES-Aero tool for aerodynamic drag simulation that is available as part of the Star-CD software package. The surface of the standard configuration GCM is defined using approximately 500,000 triangular surface elements based upon CAD data representations taken from optical scans of the actual model. A computational domain, which as external dimensions that are based on the cross-sectional dimensions of the wind tunnel, is developed based upon this surface definition using a semi-automated process that begins by creating a hexahedral mesh that is successively refined in smaller zones around vehicle, with integral cell coupling employed at the interfaces between zones. The dimensions of hexahedral elements that make up the zone immediately surrounding the vehicle are specified by user as the near 
vehicle cell size. The mesh elements near the vehicle surface are then further refined based upon local surface features identified by the user or selected automatically based on curvature or gap width. The user specifies a minimum allowable cell size that limits the refinement of the mesh in this step.

Using this locally refined hexahedral mesh, the original surface is "wrapped" by projecting the hexahedral mesh onto the original surface. The "wrapped" surface definition is then volumetrically expanded to create a subsurface which is used to cut away the portions of the locally-refined hexahedral mesh that fall inside the vehicle. A brick and prism cell extrusion layer is then created to fill the gap between the sub-surface and the "wrapped" surface. In this way, the polyhedral cut cells are removed some distance from the surface, and a consistent $\mathrm{y}^{+}$value between approximately 20 and 200, can be maintained regardless of grid resolution, insuring that the computational meshes are suitable for the turbulence models used in these studies. A final step further refines the wake region and the underbody region in order to better capture a steady state representation of important

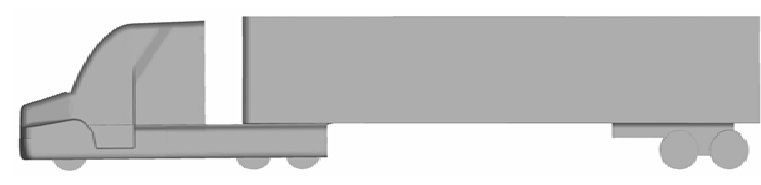

Figure 1. Generic Conventional Model (GCM)

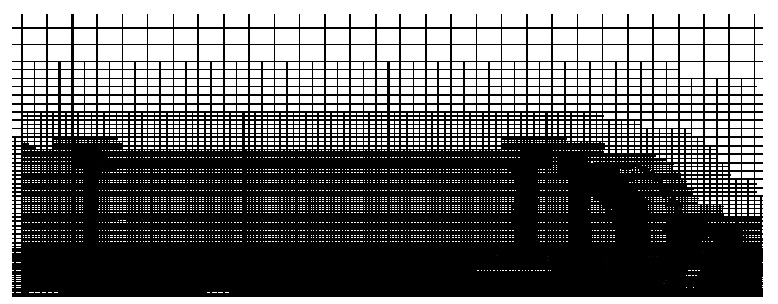

Figure 2. Example of computational mesh structure used in the simulation of the aerodynamic characteristics of the Generic Conventional Model (GCM).

flow features. An example of the mesh construction of the computational domain used in the GCM simulations is shown in Figure 2.

Using locally-refined, face-coupled computational domains with substantial numbers of non-hexahedral cells makes the standard practice of evaluating grid convergence by uniformly refining the entire mesh in all directions intractable. In the computational meshes used in these studies, two separate parameters determine the size of the mesh. Mesh sensitivity analyses included in these studies examine the effects of changes in the near-vehicle cell size and minimum cell size parameters on the prediction of the drag coefficient. However, this is not equivalent to the traditional grid convergence study because the grid is not uniformly refined in all directions throughout the domain and the vehicle surface definition cannot be exactly maintained for all models since the final surface definition is dependent upon the local refinement of the computational mesh.

\subsection{COMPUTATIONAL REQUIREMENTS}

Models are constructed using a 64 -bit $2.8 \mathrm{GHz}$ Xeon Linux workstation with $8 \mathrm{~GB}$ of RAM. The construction of the most coarsely-meshed models included in this study, from IGS formatted CAD data to final model, requires approximately 3 hours and peak memory usage is approximately $1.0 \mathrm{~GB}$. The most finely-meshed models requires approximately 12 hours and the peak memory usage is approximately $5 \mathrm{~GB}$. Since the automated mesh wizard included with the software package is used, little intervention is required by the user during this process. As with any software, initial models created by a novice user will likely require a larger initial time investment. All models employed in these studies are used as supplied from the automated tool with no manual repair or modification.

The Nuclear Engineering Division maintains a Beowulf cluster for performing engineering mechanics, fluid dynamics, and reactor engineering analyses. The cluster consists of three front-end (i.e., control) nodes and seventy-five compute nodes. One of the front-end nodes is a 32-bit servers contains dual Athlon MP 2.2GHz processors and $4 \mathrm{~GB}$ of memory. The two remaining front ends are 64-bit front-end servers: one with dual Itanium 2 processors and 24 Gigabytes of memory, the other with dual Xeon processors and 8 gigabytes of memory. The cluster's file server provides nearly 1 Terabyte of home file system space. Each of the 75 compute nodes has a $3.2 \mathrm{GHz}$ Pentium IV processor with $2 \mathrm{~GB}$ of memory. All of the machines in the cluster are interconnected via Gigabit Ethernet. All of the systems run RedHat Enterprise Linux.

\section{BRIEF SUMMARY OF PRIOR RESULTS}

Initial studies focused on establishing the validity of commercial CFD software for the prediction of the aerodynamic characteristics of a tractor-trailer vehicle. This previous effort included a mesh sensitivity study considering the effect of near vehicle cell size and minimum cell size on the accuracy of aerodynamic characteristics as well as the impact of turbulence model selection and the use of half vehicle versus full vehicle models. Additional studies have examined the ability to predict the impact of cross-winds on aerodynamic performance.

\subsection{COMPUTATIONAL MESH SENSITIVITY}

A series of studies have been completed to evaluate sensitivity of the predictive accuracy to selection of the two primary characteristic dimensions of the generated computational mesh: the near vehicle cell size and the minimum cell size. The near-vehicle cell size defines the dimensions of the cells in the region of tunnel-aligned hexahedral brick cells closest to the model surface. The 
minimum cell size is the limit applied to the automatic refinement of the region immediately adjacent to the vehicle surface and defines the smallest cell that can be used to capture local surface characteristics.

To assess the impact of the near-vehicle cell size, a series of parametric simulations was completed specifying nearvehicle cell sizes between $6 \mathrm{~mm}$ and $10 \mathrm{~mm}$ for the $1 / 8^{\text {th }}$ scale GCM. Results, summarized in table 1, indicate that the drag coefficient can be predicted with acceptable accuracy using a near vehicle cell size of $6 \mathrm{~mm}$. Furthermore, coarser meshes using near vehicle cell sizes as large as $12 \mathrm{~mm}$ can likely be used for initial coarse evaluations and trending.

Based on these results, an additional study was completed to evaluate the impact of the minimum cell size. The default minimum cell size in the previous study was $1 / 8$ the nearvehicle cell size. In this study the minimum cell size was reduced to determine whether the same computational accuracy observed in the $6 \mathrm{~mm}$ case could be achieved using a smaller number of computational cells. When the minimum cell size in the $8 \mathrm{~mm}$ case was reduced from $1 \mathrm{~mm}$ to $0.5 \mathrm{~mm}$, the accuracy of the drag coefficient prediction improved from 4.2 percent error to 1.0 percent error. This level accuracy was achieved using 30\% fewer computational cells than in the most refined model in the nearvehicle cell size study.

\subsection{TURBULENCE MODEL EFFECTS}

In all simulations completed for the computational mesh sensitivity studies, the high Reynolds number $\mathrm{k}-\varepsilon$ turbulence model was used in conjunction with a standard logarithmic wall function for the prediction of turbulent kinetic energy and eddy diffusivity. While the high Reynolds number k- $\varepsilon$ turbulence model is a robust general purpose turbulence model, the strong adverse pressure gradients and large flow recirculation regions associated with the GCM geometry may limit the applicability of steady state RANS modeling strategies. Using the computational mesh with a near vehicle cell size of $8 \mathrm{~mm}$ and a near wall cell size limit of $0.5 \mathrm{~mm}$, simulations of the aerodynamic characteristics of the GCM model were repeated using five steady RANS turbulence models and their associated wall functions: 1) the standard high-Reynolds number $\mathrm{k}-\varepsilon$ model with logarithmic wall function, 2) the Menter k- $\omega$ SST model, 3) the renormalization group (RNG) formulation of the $\mathrm{k}-\varepsilon$ model, 4) the Chen formulation of the $\mathrm{k}-\varepsilon$ model, and 5) the quadratic formulation of the $\mathrm{k}-\varepsilon$ model. Drag coefficients predicted using each of the selected steady-RANS turbulence models are shown in Table 2. Comparisons of the predicted pressure coefficient distributions when using the selected turbulence models are shown in Figure 3. The differences in the predicted drag coefficient are largely a result of localized discrepancies in the surface pressure coefficient predictions in the regions of separated flow, with the largest discrepancies appearing in the underbody region just behind the tractor.
Table 1. Effects of Near-Vehicle Cell Size Parameter on Accuracy of Drag Coefficient Prediction.

\begin{tabular}{|c|c|c|}
\hline $\begin{array}{c}\text { Near-Vehicle } \\
\text { Cell Size }(\mathrm{mm})\end{array}$ & $\begin{array}{c}\text { Predicted Drag } \\
\text { Coefficient }\end{array}$ & $\begin{array}{c}\text { Error in Drag } \\
\text { Coefficient }\end{array}$ \\
\hline experiment & 0.398 & 12.0 \\
\hline 16 & 0.449 & 10.3 \\
\hline 12 & 0.441 & 4.9 \\
\hline 10 & 0.418 & 4.2 \\
\hline 8 & 0.415 & 1.7 \\
\hline 6 & 0.405 & \\
\hline
\end{tabular}

Table 2. Results of evaluation of two-equation turbulence models for prediction of drag coefficients for the GCM geometry.

\begin{tabular}{|c|c|c|}
\hline Turbulence Model & $\begin{array}{c}\text { Predicted } \\
\text { Drag } \\
\text { Coefficient }\end{array}$ & $\begin{array}{c}\text { Percent } \\
\text { Error in } \\
\text { Prediction }\end{array}$ \\
\hline Experiment & 0.398 & -- \\
\hline $\begin{array}{c}\text { High-Reynolds } \\
\text { Number k-epsilon } \\
\text { Model }\end{array}$ & 0.402 & 1.0 \\
\hline $\begin{array}{c}\text { Menter k- } \omega \text { SST } \\
\text { model }\end{array}$ & 0.401 & 0.8 \\
\hline RNG model & 0.389 & 2.3 \\
\hline Chen's model & 0.3919 & 1.61 \\
\hline Quadratic model & 0.3815 & 4.32 \\
\hline
\end{tabular}

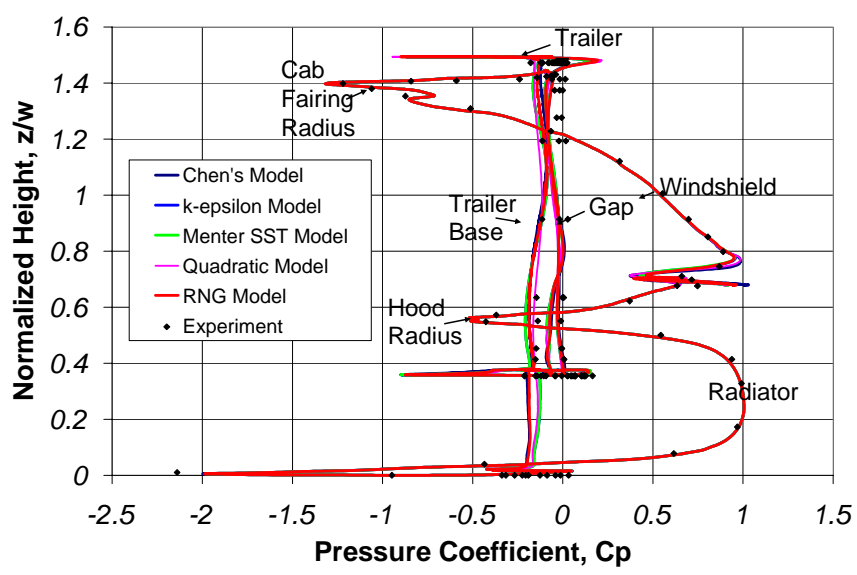

Figure 3. Comparison of predicted pressure coefficient distributions on the vehicle surface with experimental data for selected turbulence models. 
The effects of cross-winds on the vehicle performance are evaluated by rotating the model in the wind tunnel to introduce an effective yaw angle between the wind direction and the vehicle direction. In the wind tunnel experiments, yaw angles between 14 degrees and -14 degrees were considered. In the experiments, a low drag state is observed at low yaw angles. For yaw angles greater than 3 degrees a higher drag state was observed, where large flow separation zones begin to form along the leeward side of both the tractor and trailer, introducing significant turbulent instability into the flow field. The instability is further exacerbated by the formation of a highly turbulent jet through the gap between the tractor and trailer which washes over the logical separation points on the leeward side of the trailer, extending the separation zone.

Using this data for comparison, a series of simulations were completed to evaluate the effects of the computational mesh parameters on predictive accuracy at yaw angles greater than zero. Results of the mesh sensitivity study are summarized in Figure 4. These studies show that the transition between the high and low drag state can be accurately captured using the methodology developed for the GCM at zero yaw angle. Furthermore, the studies demonstrate that the aerodynamic coefficients of the vehicle can be predicted within a few percent error when sufficient resolution is used near the vehicle surface. Additional simulations included in this study indicate that little difference in drag coefficient predictions is observed for cases using the $8 \mathrm{~mm}$ near vehicle cell size when the minimum cell size is further reduced from $0.5 \mathrm{~mm}$ to $0.25 \mathrm{~mm}$. 


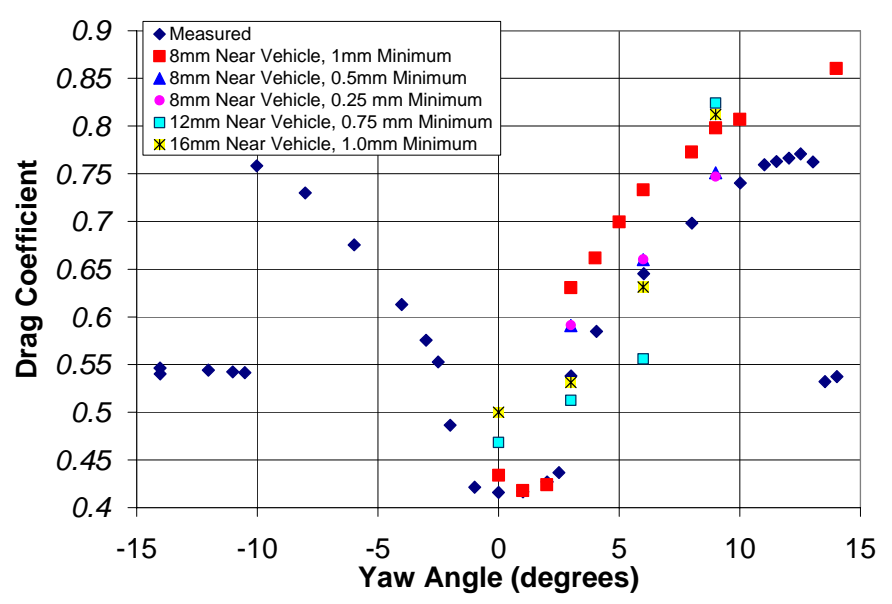

Figure 4. Comparison of Drag Coefficient Predictions as a Function of Yaw Angle and Mesh Size Parameters.

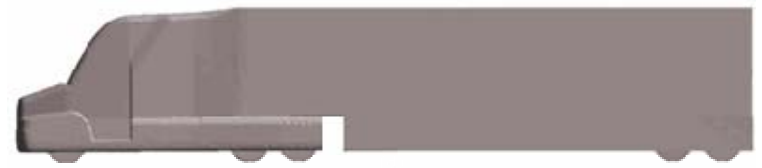

Figure 5. “GTS" Configuration of the GCM, with Full Gap Fairing and Trailer Belly Box.

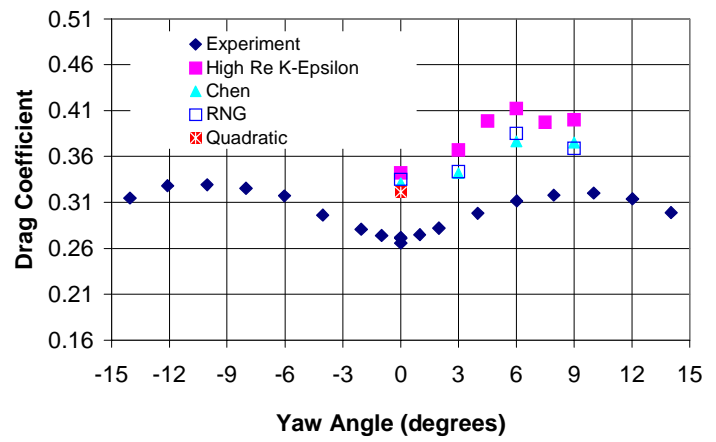

Figure 6. Drag Coefficient Predictions for the "GTS" Configuration of the GCM, as a Function of Yaw Angle and Turbulence Model Selection.

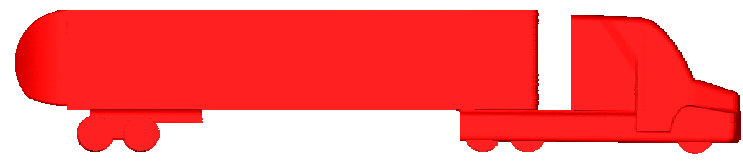

Figure 7. Modified GCM Geometry with Ogive Boat Tail.

Table 3. Summary of Drag Coefficient Predictions for the GCM Geometry with Ogive Boat Tail.

\begin{tabular}{|c|c|c|}
\hline Near Vehicle Cell Size & Near Wall Cell Size & Drag Coefficient \\
\hline $12 \mathrm{~mm}$ & $2 \mathrm{~mm}$ & 0.4179 \\
\hline $8 \mathrm{~mm}$ & $1 \mathrm{~mm}$ & 0.4116 \\
\hline 6 & $0.5 \mathrm{~mm}$ & 0.3975 \\
\hline
\end{tabular}

\section{PREDICTION OF CHANGES IN AERODYNAMIC CHARACTERISTICS}

Building on the foundation of prior studies, the practices and procedures developed through the analyses of baseline GCM geometry have been applied to studies for a number of alternative configurations. These studies include the evaluation of add on devices, the assessment of impacts of radiator size and an investigation of the impacts of flow through the grille on drag coefficients.

\section{1 "GTS" CONFIGURATION OF THE GCM}

As an initial application of the modeling strategy to alternative configurations, simulations were completed for the so-called "GTS" configuration of the GCM geometry, shown in Figure 5. This configuration includes a full fairing between the tractor and trailer and a belly box under the trailer. While this configuration is not practical for deployment, it does provide a very low drag test of the predictive capability of the CFD models. Using the baseline meshing strategy with a near vehicle cell size of $8 \mathrm{~mm}$ and a minimum cell size of $0.5 \mathrm{~mm}$, simulations were completed using 4 different steady RANS turbulence models: the standard high-Reynolds number kepsilon model, the Chen model, the RNG model, and the Quadratic model. Results are summarized in Figure 6. The error between predicted and measured coefficients ranges from approximately 10 to 30 percent. Additional studies examining mesh refinement sensitivity show little change in predictions with additional refinement near the vehicle surface or in the model as a whole. Examination of detailed flow and surface pressure results indicate that the larger error may be a consequence of the extremely low drag coefficient and the increasing importance of the base drag at the rear of the trailer. Prior studies have shown that the largest error in computational predictions when using this approach occurs at base of the trailer. For very low drag coefficient configurations, more advanced turbulence modeling strategies should be investigated.

\subsection{OGIVE BOATTAIL}

Working with a commercial partner, Aerovolutions Inc., a CAD geometry based on the GCM with a commerciallymarketed inflatable ogive boat tail device attached to the trailer was developed, as shown in Figure 7. Simulations using this geometry were completed using three different computational mesh configurations. Results are summarized in Table 3 . When compared with results for the standard configuration of the GCM using comparable mesh densities, a drag coefficient reduction of $7 \%$ is expected, which would correspond to a fuel savings of $3.5 \%$. These predictions are consistent with claims based on wind tunnel and road tests by Aerovolution.

The impact of the device on the wake behind the vehicle is quite dramatic, with the wake closing shortly behind the vehicle rather than many vehicle lengths downstream, as shown in the comparison between results with and without the device in 
Figure 8. While this effect should improve driving conditions a vehicle length downstream, as with most trailer boat tail devices, 
the more energetic turbulence in the reduced-length wake may negatively impact driving conditions for passenger cars near the rear of the vehicle.

\subsection{CHANGES IN RADIATOR/GRILLE DIMENSIONS}

To meet more restrictive EPA emissions requirements, manufacturers are likely to substantially redesign engine cooling packages to reject more of the engine heat that is currently carried away by the exhaust. An increase in radiator size is likely to result. To quantify the potential impact of this change on drag related parasitic energy losses, a series of modified GCM geometries have been developed with modified radiator or grille dimensions. In these simulations, the grille is completely closed and flow through the engine compartment is neglected. However, the effect of flow through the radiator has been quantified in other studies to be discussed in the following section.

Four different parametric cases have been considered: a 10 percent increase in the height of the radiator, a 10 percent reduction in the height of the radiator, a 10 percent increase in the width of the radiator and 10 percent reduction in the width of the radiator. In all cases, the hood angles are adjusted to be compatible with the modified grille dimensions and all other dimensions are maintained so that any observed change in performance can be directly attributed to the change in radiator size. All models use the baseline mesh parameters, with a near vehicle cell size of $8.0 \mathrm{~mm}$ and a minimum cell size of $0.5 \mathrm{~mm}$. Results for the modified geometries at yaw angles of 0 and 6 degrees are summarized in Table 4 . No significant change in drag coefficient is observed for any of the four cases. Review of detailed pressure and force distributions, such as those seen in Figure 9, confirms that high pressure areas on the grill are simply relocated to or from the windshield or the sides and top of the hood.

\subsection{EFFECTS OF FLOW THROUGH RADIATOR/GRILLE}

In all prior simulations, the effect of the flow of air through the grille and radiator has been neglected on the assumption the radiator is so dense that it essentially appears as a solid surface to the impinging flow. To evaluate the effect of the underhood flow, a modified GCM geometry was developed with an open grille, as shown in Figure 10. An additional outlet boundary condition was placed at the back of the open space behind the grille, and the radiator was represented by a porous baffle between the grille and the outlet. The radiator was assumed to have a porosity of $33 \%$ and the outlet condition was specified based on the ratio of the areas of the new outlet to the primary outlet.

Simulations of the modified geometry at zero degrees yaw were completed using a computational mesh based on the baseline mesh parameters, so that the near vehicle cell size was $8 \mathrm{~mm}$ and the minimum cell size was $0.5 \mathrm{~mm}$. The standard high-Reynolds number k-epsilon model was specified. The predicted drag coefficient for this case was 0.4115 , which is a 1.2 percent increase over the standard configuration when compared to simulations using comparable computational mesh density. Since this value is within the anticipated error of the calculation, the change in configuration does not result in a statistically significant change in aerodynamic performance.

\section{CONCLUSIONS}

The studies described herein provide a demonstration of the applicability of the experience developed in the analysis of the standard

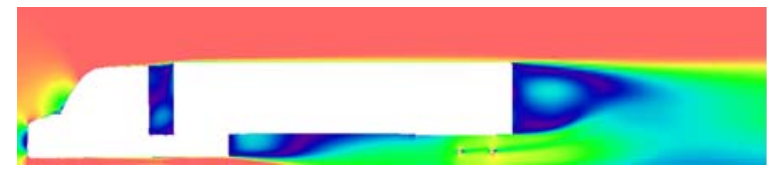

(a) Standard GCM

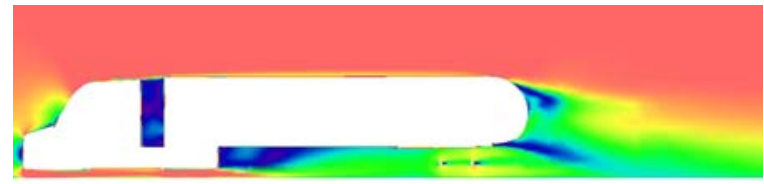

(b) GCM + Boat Tail

Figure 7. Comparison of Velocity Magnitude Predictions for the Standard GCM Geometry and for the Modified GCM Geometry with Ogive Boat Tail.

Table 4. Impact of Changes in Radiator/Grille Dimensions on Drag Coefficient.

\begin{tabular}{|c|c|c|}
\hline Configuration & Drag @ $0^{\circ}$ Yaw & Drag @ $6^{\circ}$ Yaw \\
\hline Nominal & 0.4061 & 0.7861 \\
\hline Height $+10 \%$ & 0.4041 & 0.8208 \\
\hline Height $-10 \%$ & 0.4022 & 0.8105 \\
\hline Width $+10 \%$ & 0.4097 & 0.7423 \\
\hline Width $-10 \%$ & 0.4097 & 0.7392 \\
\hline
\end{tabular}
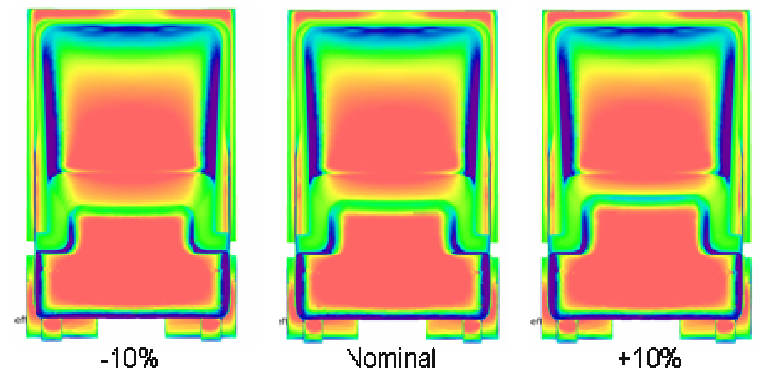

Figure 9. Response of Surface Pressure Distribution to Changes in Radiator Height.

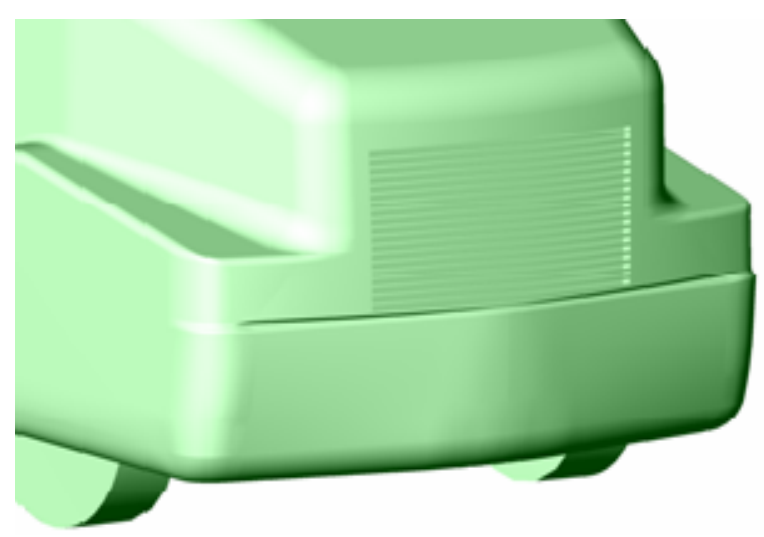

Figure 10. Modified GCM Geometry with Open Grille and Flow-through Radiator. 
configuration of the Generic Conventional Model. The modeling practices and procedures developed in prior efforts have been applied directly to the assessment of new configurations including a variety of geometric modifications and add-on devices. Application to the low-drag "GTS" configuration of the GCM has confirmed that the error in predicted drag coefficients increases as the relative contribution of the base drag resulting from the vehicle wake to the total drag increases and it is recommended that more advanced turbulence modeling strategies be applied under those circumstances. Application to a commercially-developed boat tail device has confirmed that this restriction does not apply to geometries where the relative contribution of the base drag to the total drag is reduced by modifying the geometry in that region. Application to a modified GCM geometry with an open grille and radiator has confirmed that the underbody flow, while important for underhood cooling, has little impact on the drag coefficient of the vehicle.

Furthermore, the evaluation of the impact of small changes in radiator or grille dimensions has revealed that the total drag is not particularly sensitive to those changes. This observation leads to two significant conclusions. First, a small increase in radiator size to accommodate heat rejection needs related to new emissions restrictions may be tolerated without significant increases in drag losses. Second, efforts to reduce drag on the tractor requires that the design of the entire tractor be treated in an integrated fashion. Simply reducing the size of the grille will not provide the desired result, but the additional contouring of the vehicle as a whole which may be enabled by the smaller radiator could have a more significant effect.

\section{ACKNOWLEDGMENTS}

This work has been completed under the auspices of the U.S. Department of Energy by the University of Chicago as Operator of Argonne National Laboratory ("Argonne") under Contract No. W-31-109-ENG-38. The authors would like to acknowledge the generous support of DOE program manager Lee Slezak and the entire Heavy Vehicle Aerodynamics Team.

\section{REFERENCES}

11. Star-CD, CD-adapco group, Melville, NY.

12. Satran, D., "An Experimental Study of the Generic Conventional Model (GCM) in the NASA Ames 7-by-10-Foot Wind Tunnel," United Engineering Foundation Conference on the Aerodynamics of Heavy Vehicles: Trucks, Buses, and Trains, United Engineering Foundation, New York, 2002.

13. W. David Pointer, Tanju Sofu, and David Weber, "Development of Guidelines for the Use of Commercial CFD in Tractor-Trailer Aerodynamic Design," 2005 SAE Commercial Vehicle Engineering Conference, Chicago, IL, November 2005. (SAE Paper No. 05CV-120).

14. W. David Pointer, "Evaluation of Commercial CFD Code Capabilities for Prediction of Heavy Vehicle Drag Coefficients," Proceedings of the 2004 AIAA Fluid Dynamics Conference and Exhibition, Portland, Oregon, June 2004. (AIAA-2004-2254) 